\title{
Temperature and Precipitation Variance in CMIP5 Simulations and Paleoclimate Records of the Last Millennium ${ }^{\circ}$
}

\author{
Luke A. PARsons AND Garrison R. LOOPE \\ Department of Geosciences, The University of Arizona, Tucson, Arizona \\ JONATHAN T. OVERPECK \\ Department of Geosciences, and Department of Hydrology and Atmospheric Sciences, \\ The University of Arizona, Tucson, Arizona \\ TOBY R. AUlt \\ Department of Earth and Atmospheric Sciences, Cornell University, Ithaca, New York \\ RONALD STOUFFER \\ Department of Geosciences, The University of Arizona, Tucson, Arizona \\ Julia E. COLE \\ Department of Geosciences, and Department of Hydrology and Atmospheric Sciences, \\ The University of Arizona, Tucson, Arizona
}

(Manuscript received 1 December 2016, in final form 17 April 2017)

\begin{abstract}
Accurate assessments of future climate impacts require realistic simulation of interannual-century-scale temperature and precipitation variability. Here, well-constrained paleoclimate data and the latest generation of Earth system model data are used to evaluate the magnitude and spatial consistency of climate variance distributions across interannual to centennial frequencies. It is found that temperature variance generally increases with time scale in patterns that are spatially consistent among models, especially over the mid- and high-latitude oceans. However, precipitation is similar to white noise across much of the globe. When Earth system model variance is compared to variance generated by simple autocorrelation, it is found that tropical temperature variability in Earth system models is difficult to distinguish from variability generated by simple autocorrelation. By contrast, both forced and unforced Earth system models produce variability distinct from a simple autoregressive process over most high-latitude oceans. This new analysis of tropical paleoclimate records suggests that low-frequency variance dominates the temperature spectrum across the tropical Pacific and Indian Oceans, but in many Earth system models, interannual variance dominates the simulated central and eastern tropical Pacific temperature spectrum, regardless of forcing. Tropical Pacific model spectra are compared to spectra from the instrumental record, but the short instrumental record likely cannot provide accurate multidecadal-centennial-scale variance estimates. In the coming decades, both forced and natural patterns of decade-century-scale variability will determine climaterelated risks. Underestimating low-frequency temperature and precipitation variability may significantly alter our understanding of the projections of these climate impacts.
\end{abstract}

Supplemental information related to this paper is available at the Journals Online website: https://doi.org/10.1175/JCLI-D-160863.s1.

Corresponding author: Luke A. Parsons, lukeaparsons@email. arizona.edu

\section{Introduction}

Many instrumental and paleoclimate records suggest that the spectrum of climate variations can be described by power-law scaling (e.g., Blender and Fraedrich 2003; Fraedrich and Blender 2003; Ditlevsen et al. 1996; Pelletier 1998; Pelletier and Turcotte 1997; Huybers and

DOI: 10.1175/JCLI-D-16-0863.1

(c) 2017 American Meteorological Society. For information regarding reuse of this content and general copyright information, consult the AMS Copyright Policy (www.ametsoc.org/PUBSReuseLicenses). 
Curry 2006; Franke et al. 2013; Laepple and Huybers 2013, 2014a,b; Ault et al. 2013b, 2014). A power-law relationship implies that variations in climate (i.e., temperature or precipitation) exhibit higher (or lower) amplitudes at lower frequencies (Huybers and Curry 2006). However, comparative studies among climate model and observation data have indicated that there may be up to an order of magnitude mismatch between proxy and simulated temperature and precipitation variability at decade-century time scales (e.g., Ault et al. 2013a,b; Franke et al. 2013; Laepple and Huybers 2014b).

Understanding variability at these time scales is important for studies of climate change, including analyses of detection and attribution of climate change impacts. Additionally, understanding variability at these time scales is important for simulation of abrupt change (Valdes 2011; Shuman 2012), prolonged drought (Pelletier and Turcotte 1997; Ault et al. 2013b, 2014), and lowerfrequency climate variations (e.g., Thornalley et al. 2009). If climate models underestimate variability on decadalcentennial time scales, they will underestimate the likelihood of abrupt change, megadrought, and other extreme climate events.

Beyond climate prediction, understanding the true shape of local precipitation and temperature spectra is integral to our understanding of climate itself. For instance, where is long-period variability based on coupled dynamics, and where does variability arise solely from autocorrelation and smoothing of weather noise? Manabe and Stouffer (1996) showed that dampened weather noise can explain much of the shorter-period temperature variability in a coupled atmosphere-ocean model. However, ocean circulation may lead to significant longer-period (centennial scale) regional temperature variability (Bjerknes 1964; Manabe and Stouffer 1996).

Here we expand the analysis of the continuum of climate variability to multiple models from phase 5 of the Coupled Model Intercomparison Project (CMIP5) and paleoclimate records. We test whether the latest Earth system models generate local low-frequency temperature and precipitation variability greater than variability expected from a simple autocorrelated process. The tendency for many climate variables to exhibit some degree of "redness" (i.e., increased variance at longer time scales) is well documented (Kutzbach and Bryson 1974; Blender and Fraedrich 2003; Fraedrich and Blender 2003; Ditlevsen et al. 1996; Pelletier 1998; Pelletier and Turcotte 1997; Huybers and Curry 2006; Franke et al. 2013; Laepple and Huybers 2013; Ault et al. 2013b). In its simplest form, this tendency may arise from the large thermal capacity of the oceans and cryosphere, which integrate high-frequency "white noise" forcings, including weather, interannual variations, and even short-lived cooling from volcanic eruptions (Hasselmann 1976; Newman et al. 2003; Newman et al. 2016; Sigl et al. 2015). We evaluate the distribution of temperature and precipitation variance simulated by coupled Earth system models against the null hypothesis that low-frequency variations are generated exclusively from a monthly lag- 1 autocorrelated [AR(1)] process (e.g., ocean damping of weather noise). We also test whether pre-anthropogenic external forcings of the last millennium significantly influence modeled variance distributions.

\section{Data and methods}

\section{a. CMIP5 simulations}

We used gridded surface temperature (TS) and precipitation (PR) model output from 10 all-forcing CMIP5 last millennium (CMIP5 LM) and 10 all-forcing NCAR CESM1.1(CAM5) last millennium ensemble (CESM LME) simulations (Taylor et al. 2012; Schmidt et al. 2012; Otto-Bliesner et al. 2015). In addition to the allforcing CESM LME simulations, we used one control run and 17 single-forcing simulations from the CESM LME, including volcanic $(N=5)$, solar $(N=3)$, greenhouse gas $(N=3)$, orbital $(N=3)$, and land-use and land-cover changes $(N=3)$ to examine the influence of external forcing on low-frequency climate variability. We also compared all available NASA GISS-E2-R last millenium (LM) simulations with and without volcanic forcing. We only compared last millennium forcing scenarios in CESM and GISS-E2-R because these were the only simulations available at the time of our analysis. The LM experiment typically spans the period 850-2005 Common Era (CE), but here we limited our analysis to model data covering the time period $850-1850 \mathrm{CE}$ to exclude the influence of anthropogenic warming on long-period variability. We also used CMIP5 preindustrial control (CMIP5 PIC) simulations (Taylor et al. 2012) that span at least $500 \mathrm{yr}$ to estimate unforced interannual-centennial-scale variability from the same modeling groups that conducted the LM experiment (Table 1). Finally, we used CMIP5 historical (CMIP5 HIST) simulations to estimate forced interannualcentennial-scale temperature variability during the time period 1850-2005 CE. Although we calculated $\beta$ for all models and ensemble members listed in Table 1, we show only three representative ensemble member maps from the CESM LME in the main text to highlight our results. We also show results from the 10 CMIP5 LM members and the same 10 CMIP5 PIC models in the main text to highlight the forcing versus control differences; additional results are included in the supplemental material. 
TABLE 1. CMIP5 simulations, experiment types, run lengths, and variables used in our analysis. NCAR CESM1(CAM5) last millennium ensemble (total of 29 simulations), CMIP5 last millennium (past 1000), and CMIP5 preindustrial (predin) control runs. Boldface font indicates the 10 preindustrial control runs used in mean maps in Fig. 8; these are the same models that ran the last millennium experiment. The remainder of the CMIP5 preindustrial control simulation results are shown in the supplemental material. (Expansions of acronyms are available online at http://www.ametsoc.org/PubsAcronymList.)

\begin{tabular}{|c|c|c|c|c|c|c|c|}
\hline Model and run & Experiment & Forcing & Start year & End year & $N(\mathrm{yr})$ & TS & PR \\
\hline NCAR CESM1(CAM5) & LME & Full & 850 & 1849 & 1000 & $\mathrm{x}$ & $\mathrm{x}$ \\
\hline BCC_CSM1.1 & Past 1000 & Full & 850 & 1850 & 1001 & $\mathrm{x}$ & $\mathrm{x}$ \\
\hline NCAR CCSM4 & Past 1000 & Full & 850 & 1849 & 1000 & $\mathrm{x}$ & $\mathrm{x}$ \\
\hline CSIRO Mk3L-1-2 & Past 1000 & Full & 850 & 1850 & 1001 & $\mathrm{x}$ & $\mathrm{x}$ \\
\hline FGOALS-g1.0 & Past 1000 & Full & 1000 & 1999 & 1000 & $\mathrm{x}$ & $\mathrm{x}$ \\
\hline FGOALS-s2 & Past 1000 & Full & 850 & 1850 & 1001 & $\mathrm{x}$ & $\mathrm{x}$ \\
\hline GISS-E2-R (r1i1p121) & Past 1000 & Full & 850 & 1850 & 1001 & $\mathrm{x}$ & $\mathrm{x}$ \\
\hline GISS-E2-R (r1i1p1221) & Past 1000 & Full & 850 & 1850 & 1001 & & $\mathrm{x}$ \\
\hline GISS-E2-R (r1i1p122) & Past 1000 & Full & 850 & 1850 & 1001 & $\mathrm{x}$ & $\mathrm{x}$ \\
\hline GISS-E2-R (r1i1p123) & Past 1000 & No volcanic & 850 & 1850 & 1001 & $\mathrm{x}$ & $\mathrm{x}$ \\
\hline GISS-E2-R (r1i1p124) & Past 1000 & Full & 850 & 1850 & 1001 & $\mathrm{x}$ & $\mathrm{x}$ \\
\hline GISS-E2-R (r1i1p125) & Past 1000 & Full & 850 & 1850 & 1001 & $\mathrm{x}$ & $\mathrm{x}$ \\
\hline GISS-E2-R (r1i1p126) & Past 1000 & No volcanic & 850 & 1850 & 1001 & $\mathrm{x}$ & $\mathrm{x}$ \\
\hline GISS-E2-R (r1i1p127) & Past 1000 & Full & 850 & 1850 & 1001 & $\mathrm{x}$ & $\mathrm{x}$ \\
\hline HadCM3 & Past 1000 & Full & 850 & 1850 & 1001 & $\mathrm{x}$ & $\mathrm{x}$ \\
\hline IPSL-CM5A-LR & Past 1000 & Full & 850 & 1850 & 1001 & $\mathrm{x}$ & $\mathrm{x}$ \\
\hline MPI-ESM-P & Past 1000 & Full & 850 & 1850 & 1001 & $\mathrm{x}$ & $\mathrm{x}$ \\
\hline MRI-CGCM3 & Past 1000 & Full & 850 & 1850 & 1001 & $\mathrm{x}$ & $\mathrm{x}$ \\
\hline BCC_CSM1.1 & piControl & Preind & 1 & $\mathbf{5 0 0}$ & $\mathbf{5 0 0}$ & $\mathbf{x}$ & $\mathbf{x}$ \\
\hline ACCESS1.0 & piControl & Preind & 300 & 799 & 500 & $\mathrm{x}$ & $\mathrm{x}$ \\
\hline ACCESS1.3 & piControl & Preind & 250 & 749 & 500 & $\mathrm{x}$ & $\mathrm{x}$ \\
\hline BNU-ESM & piControl & Preind & 1450 & 2008 & 559 & $\mathrm{x}$ & $\mathrm{x}$ \\
\hline NCAR CCSM4 & piControl & Preind & 250 & 1300 & 1051 & $\mathbf{x}$ & $\mathbf{x}$ \\
\hline NCAR CESM1(BGC) & piControl & Preind & 101 & 600 & 500 & $\mathrm{x}$ & $\mathrm{x}$ \\
\hline CNRM-CM5 & piControl & Preind & 1850 & 2699 & 850 & $\mathrm{x}$ & $\mathrm{x}$ \\
\hline CSIRO MK3.6.0 & piControl & Preind & 1 & 500 & 500 & $\mathbf{x}$ & $\mathbf{x}$ \\
\hline CanESM2 & piControl & Preind & 2015 & 3010 & 996 & $\mathrm{x}$ & $\mathrm{x}$ \\
\hline FGOALS-g2 & piControl & Preind & 201 & 900 & 700 & $\mathbf{x}$ & $\mathbf{x}$ \\
\hline FGOALS-s2 & piControl & Preind & 1850 & 2350 & 501 & $\mathbf{x}$ & $\mathbf{x}$ \\
\hline FIO-ESM & piControl & Preind & 401 & 1100 & 700 & $\mathrm{x}$ & $\mathrm{x}$ \\
\hline GFDL-ESM2G & piControl & Preind & 1 & 500 & 500 & $\mathrm{x}$ & $\mathrm{x}$ \\
\hline GFDL-ESM2M & piControl & Preind & 1 & 500 & 500 & $\mathrm{x}$ & $\mathrm{x}$ \\
\hline GISS-E2-H & piControl & Preind & 1180 & 2949 & 780 & $\mathrm{x}$ & $\mathrm{x}$ \\
\hline GISS-E2-R & piControl & Preind & 3331 & 4530 & 850 & $\mathbf{x}$ & $\mathbf{x}$ \\
\hline HadCM3 & piControl & Preind & 800 & 2000 & 1200 & $\mathbf{x}$ & $\mathbf{x}$ \\
\hline HadGEM2-ES & piControl & Preind & 1859 & 2435 & 576 & $\mathrm{x}$ & $\mathrm{x}$ \\
\hline INM-CM4.0 & piControl & Preind & 1850 & 2349 & 500 & $\mathrm{x}$ & $\mathrm{x}$ \\
\hline IPSL-CM5A-LR & piControl & Preind & 1800 & 2799 & 1000 & $\mathbf{x}$ & $\mathbf{x}$ \\
\hline MIROC5 & piControl & Preind & 2000 & 2699 & 670 & $\mathrm{x}$ & $\mathrm{x}$ \\
\hline MPI-ESM-LR & piControl & Preind & 1850 & 2849 & 1000 & $\mathrm{x}$ & $\mathrm{x}$ \\
\hline MPI-ESM-MR & piControl & Preind & 1850 & 2849 & 1000 & $\mathrm{x}$ & $\mathrm{x}$ \\
\hline MPI-ESM-P & piControl & Preind & 1850 & 3005 & 1156 & $\mathbf{x}$ & $\mathbf{x}$ \\
\hline MRI-CGCM3 & piControl & Preind & 1851 & 2350 & $\mathbf{5 0 0}$ & $\mathbf{x}$ & $\mathbf{x}$ \\
\hline NorESM1-M & piControl & Preind & 700 & 1200 & 501 & $\mathrm{x}$ & $\mathrm{x}$ \\
\hline
\end{tabular}

\section{b. Power spectra estimation}

We estimated power spectra from model output for each grid box on the model's native grid structure to avoid the smoothing effects of regridding. We then calculated the power-law scaling parameter $\beta$ [from powerlaw relationship for frequency $f$ and variance $S(f)$, where $S(f) \propto f^{-\beta}$ ], using the methodology of Huybers and Curry (2006) and Ault et al. (2013b). We first calculated the annual mean for each gridbox time series (Figs. 1a,b). We then standardized all temperature and precipitation (using a modified version of the inverse Rosenblatt transform; Van Albada and Robinson 2007) time series to exhibit unit variance. We next estimated the power spectrum for each nondetrended time series using Thomson's multitaper method and specified 2 as 

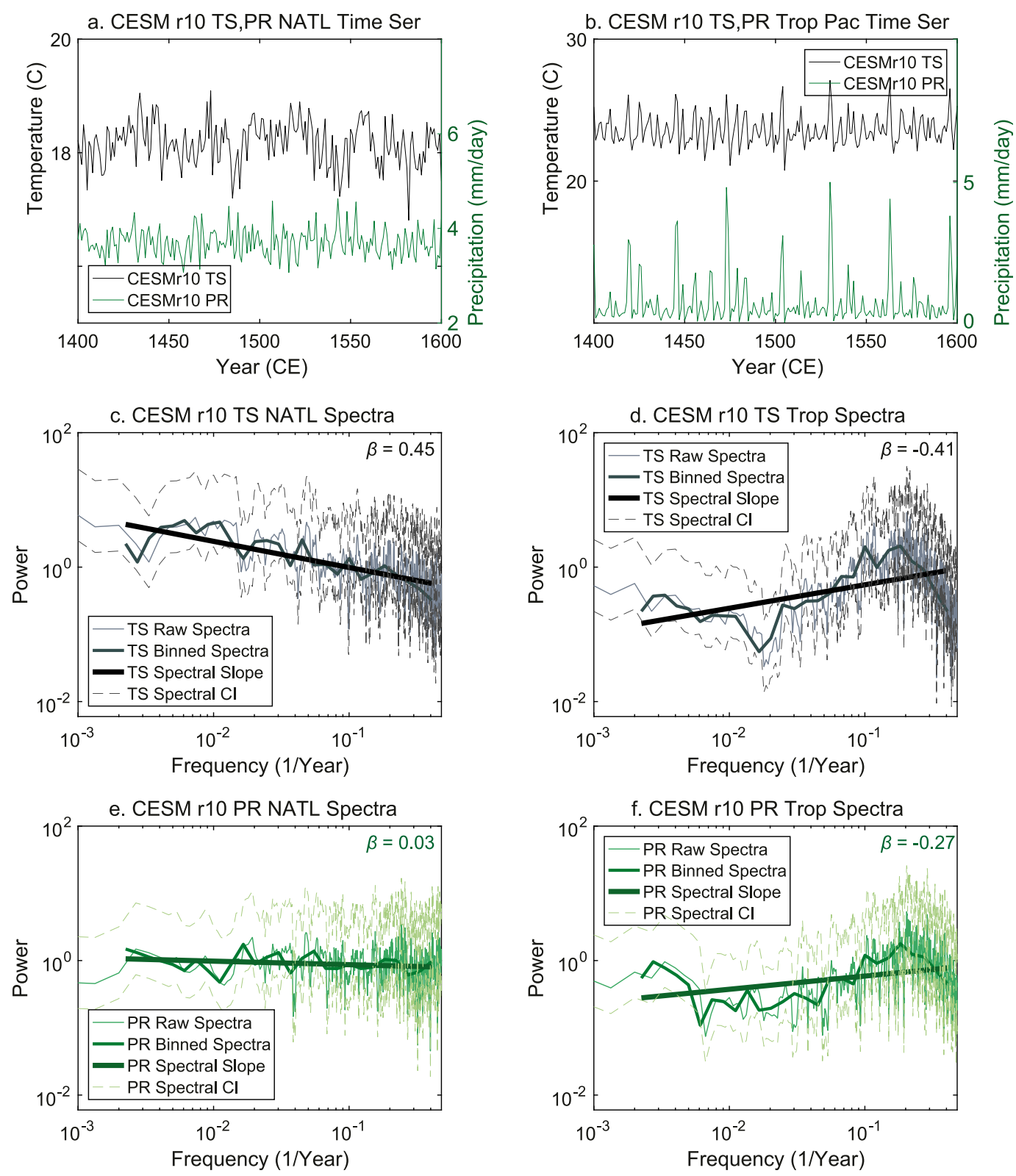

FIG. 1. Simulated temperature and precipitation time series and estimated spectra. Example of conversion of (top) annual time series to estimated (middle),(bottom) power spectra (thin lines), spectral slope (heavy solid black line), and $\beta$ value for data from (a),(c),(e) one grid box in the North Atlantic $\left(40^{\circ} \mathrm{N}, 20^{\circ} \mathrm{W}\right)$ and (b),(d),(f) one grid box in the tropical Pacific $\left(2^{\circ} \mathrm{S}, 120^{\circ} \mathrm{W}\right)$ in the CESM LME. In (a),(b), black lines indicate surface temperature (left $y$ axis) and green lines indicate precipitation (right $y$ axis). Time series in (a) and (b) are shown prior to normalization, which was done for all calculations before calculation of spectral estimation in (c)-(f). In (c)-(f), dashed lines delineate upper and lower $95 \%$ confidence bounds on spectral estimates. We used a chi-squared approach to obtain the $95 \%$ confidence bounds on the spectra.

the time-bandwidth product (Slepian sequences) used as data windows (Thomson 1982). We then binned the spectra in evenly spaced frequency bins (spaced at equal $0.2 \log$ intervals) to avoid overemphasizing high-frequency variance in regression calculations. We calculated a least squares fit line for log-transformed spectral power and frequency between interannual- (1/2 yr) and centennialscale $(1 / 500 \mathrm{yr})$ frequencies. The slope of this line in log$\log$ space equals the value of $\beta$ that we mapped in all figures (Figs. 1c-f).

We refer to a time series as "red" if its spectrum has increasing variance at lower frequencies (a negative 

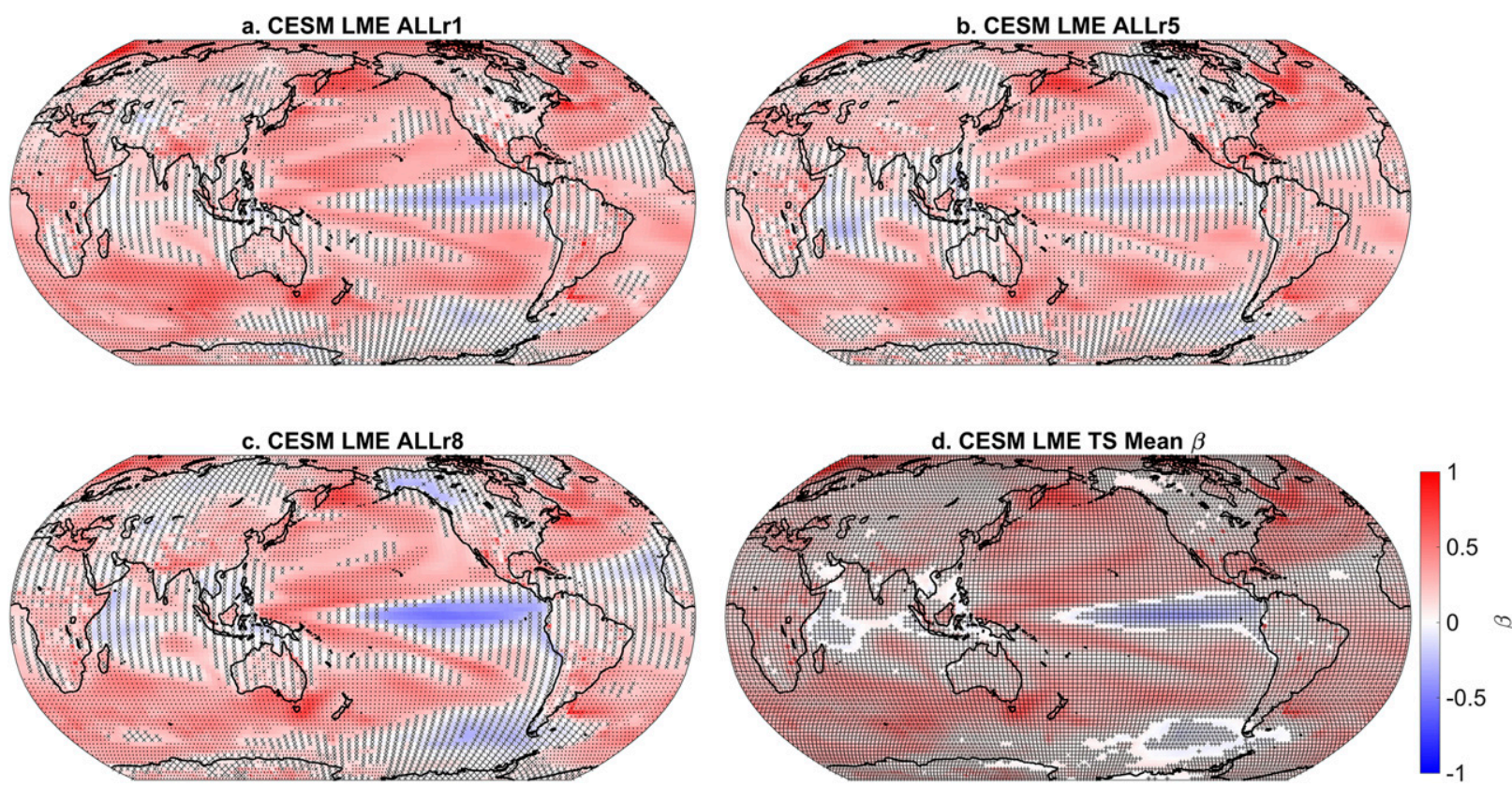

FIG. 2. (a)-(d) Maps of $\beta$ calculated for surface temperature variability in all-forcing simulations from the CESM LME. Individual run $\beta$ maps are numbered in (a)-(c); the 10-member multirun mean $\beta$ map is shown in (d) (blue to red shading indicates $\beta$ ). Stippling in individual run maps marks regions with $\beta$ values that fall outside $95 \%$ of AR(1) process $\beta$ values (see text for methods). Vertical hatching in individual run maps marks regions where the linear regression used to calculate $\beta$ is nonsignificant (power-law scaling is a poor fit; $p$ value $>0.01$ in calculation of $\beta$ ). Cross symbols $(\times)$ in mean map mark regions where at least 8 out of 10 simulations agree on the sign of $\beta$.

slope in log-log space), such as surface temperature in CESM in the North Atlantic (Fig. 1c). We refer to a time series as "blue" if its spectrum has decreasing variance at lower frequencies (a positive slope in loglog space), such as surface temperature in CESM in the tropical Pacific (Figs. 1d,f). Although certain regions appear blue on many of the maps of $\beta$, the spectral shape in these regions is generally not appropriately described by a linear fit owing to the large interannual variance peak (Figs. 1d,f). Therefore, although power-law behavior can be used to derive expected return times for extreme events (e.g., Roe and Baker 2016; Ault et al. 2013b), the apparent negative scaling in the tropics should not be used to calculate return times for extreme events owing to the lack of negative power-law scaling behavior in this region. We refer to a given time series as "white" if it roughly had equal variance at all frequencies and had a flat slope (between -0.2 and 0.2) (Ault et al. 2013b) in log-log space, such as precipitation over the North Atlantic in CESM (Fig. 1e).

After power spectra estimation and slope $\beta$ calculation for each native grid box, we then interpolated all data onto a $\sim 2^{\circ}$ horizontal grid for plotting and averaging among different models. If multiple runs from the same model were available, we calculated the multirun mean before averaging with other models. We calculated mean $\beta$ values for a given model and across models for a given experiment to find regions of model agreement (Figs. 2-4). We chose to use $\beta$ because this parameter allowed us to compare the relative powers of variability across the spectrum, as opposed to individually analyzing standard deviations of various frequencies, which would only allow us to compare distinct portions of the spectrum.

We replicated our analysis with near-surface air temperature (SAT; or reference height temperature) in CESM LME, and there was minimal difference from TS ("skin" temperature) $\beta$ values. We also calculated temperature $\beta$ between $1 / 2$ - and $1 / 100$-yr frequencies and found slight differences in magnitude, but no difference in the spatial patterns of our results. Additionally, we repeated our analysis for the CESM LME experiments after removing the linear trend from all the time series, and our $\beta$ value results did not significantly change (Fig. 5).

For the CMIP5 LM and CMIP5 PIC experiments, we excluded all models with a global mean trend (model drift) greater than $1^{\circ} \mathrm{C}$ per millennium (GFDL CM3, MIROC-ESM, HadGEM2-AO) after finding a relationship between preindustrial control simulations with a large global temperature drift and global mean temperature $\beta$ values. Once we removed models with a temperature drift greater than $1^{\circ} \mathrm{C}$ per millennium, the 

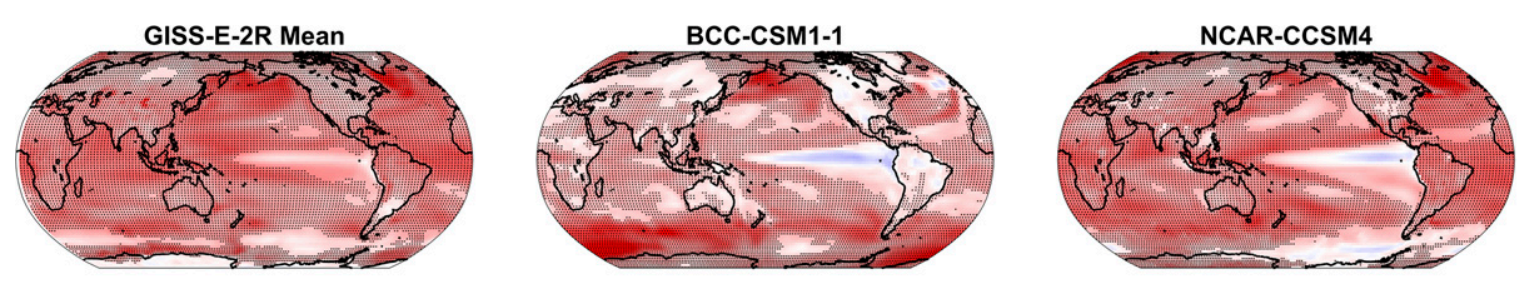

CSIRO-Mk3L-1-2

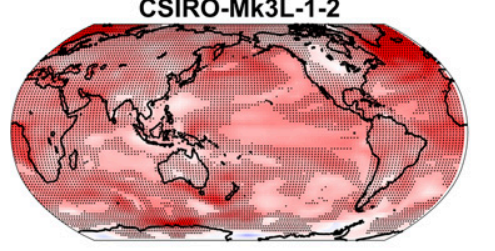

FGOALS-gl
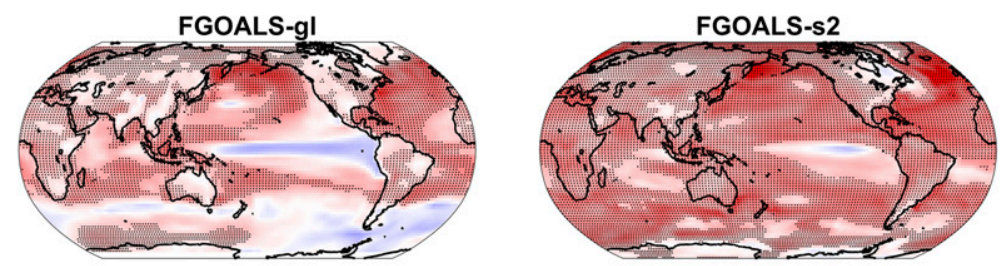

HadCM3
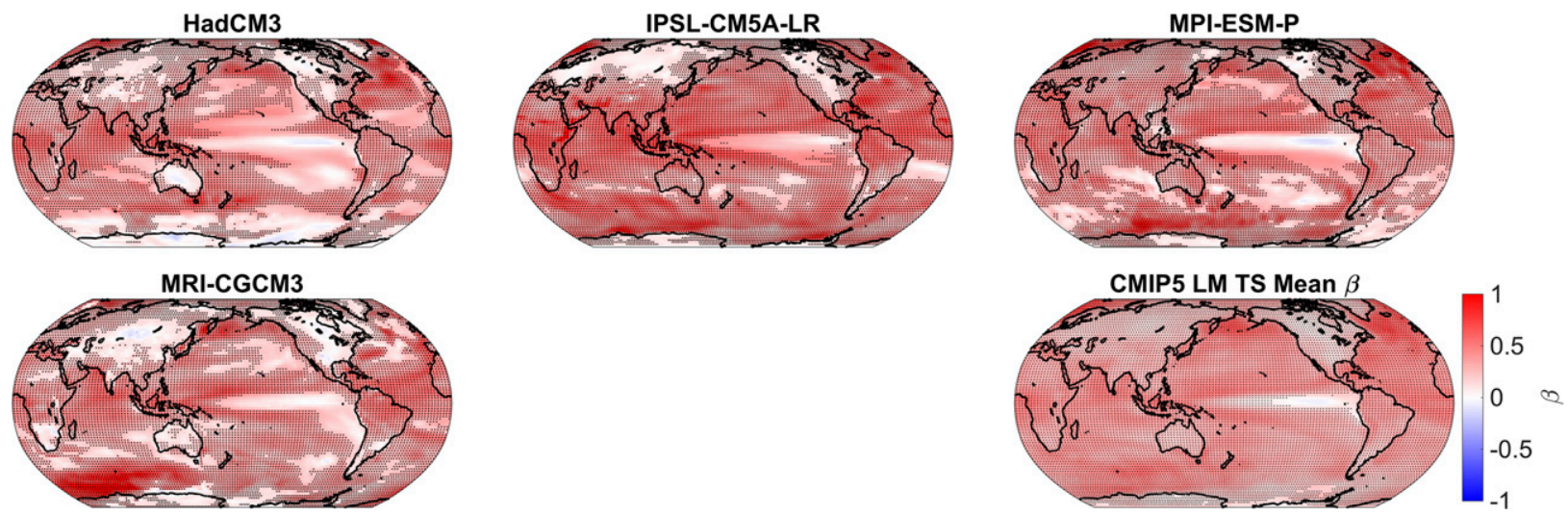

FIG. 3. Maps of surface temperature scaling $\beta$ from CMIP5 last millennium all-forcing simulations. Temperature $\beta$ maps from individual simulations are shown; (bottom right) 10 -member multimodel mean $\beta$ map is shown (blue to red shading indicates $\beta$ ). (top left) The GISSE2-R $\beta$ map reflects a multirun mean. Stippling in individual run maps marks regions with $\beta$ values that fall outside $95 \%$ of AR(1) process $\beta$ values (see text for methods). Stippling in mean map marks regions where at least 8 out of 10 simulations agree on the sign of $\beta$.

relationship between global mean temperature trend and global mean $\beta$ in CMIP5 PIC was greatly reduced. There is some degree of regional drift in many of the remaining models that slightly increases our estimates of low-frequency variability, but as in Fredriksen and Rypdal (2016), we find that removing the full time series linear trend in CMIP5 PIC models minimally impacts the distribution of $\beta$ (Fig. 5).

\section{c. Surface temperature observations}

We compared CMIP5 surface temperature spectra to spectra calculated from gridded temperature data in the Niño-3.4 $\left(5^{\circ} \mathrm{S}-5^{\circ} \mathrm{N}, 170^{\circ}-120^{\circ} \mathrm{W}\right)$, North Atlantic $\left(45^{\circ}-55^{\circ} \mathrm{N}, 50^{\circ}-20^{\circ} \mathrm{W}\right)$, South Atlantic $\left(50^{\circ}-40^{\circ} \mathrm{S}, 50^{\circ}-\right.$ $\left.20^{\circ} \mathrm{W}\right)$, and North Pacific $\left(20^{\circ}-40^{\circ} \mathrm{N}, 150^{\circ}-130^{\circ} \mathrm{W}\right)$ regions. We used the full, nondetrended time series from four instrumentally based data products: HadCRUT4 extends back to $1850 \mathrm{CE}$ (Morice et al. 2012), HadISST to 1870 CE (Rayner et al. 2003), Kaplan SST to 1856 CE (Kaplan et al. 1998), and NOAA ERSST.v4 to 1854 CE (Huang et al. 2015). SST observations are increasingly sparse farther back in time, and data coverage is particularly problematic in the South Atlantic and tropical Pacific before the mid-twentieth century (e.g., Deser et al. 2010). The SST data products statistically fill in missing observations with interpolated values based on particular methodologies that are described in the original references (e.g., Smith et al. 1996; Rayner et al. 2003; Huang et al. 2015). We show results using these data products in Figs. 6 and 7.

In Fig. 6, we show the model and observation spectra for the four ocean regions. We did not standardize these time series prior to spectral estimation so we could directly compare the magnitude of variance at a given frequency among the observed and simulated datasets. We calculated the annual mean anomalies for each time series, estimated the power spectrum for each time series, and averaged the individual spectra for each grid box to calculate the regional mean spectrum. We show the average spectrum (and 95\% confidence bounds) from the four observation datasets for each region in Fig. 6. 

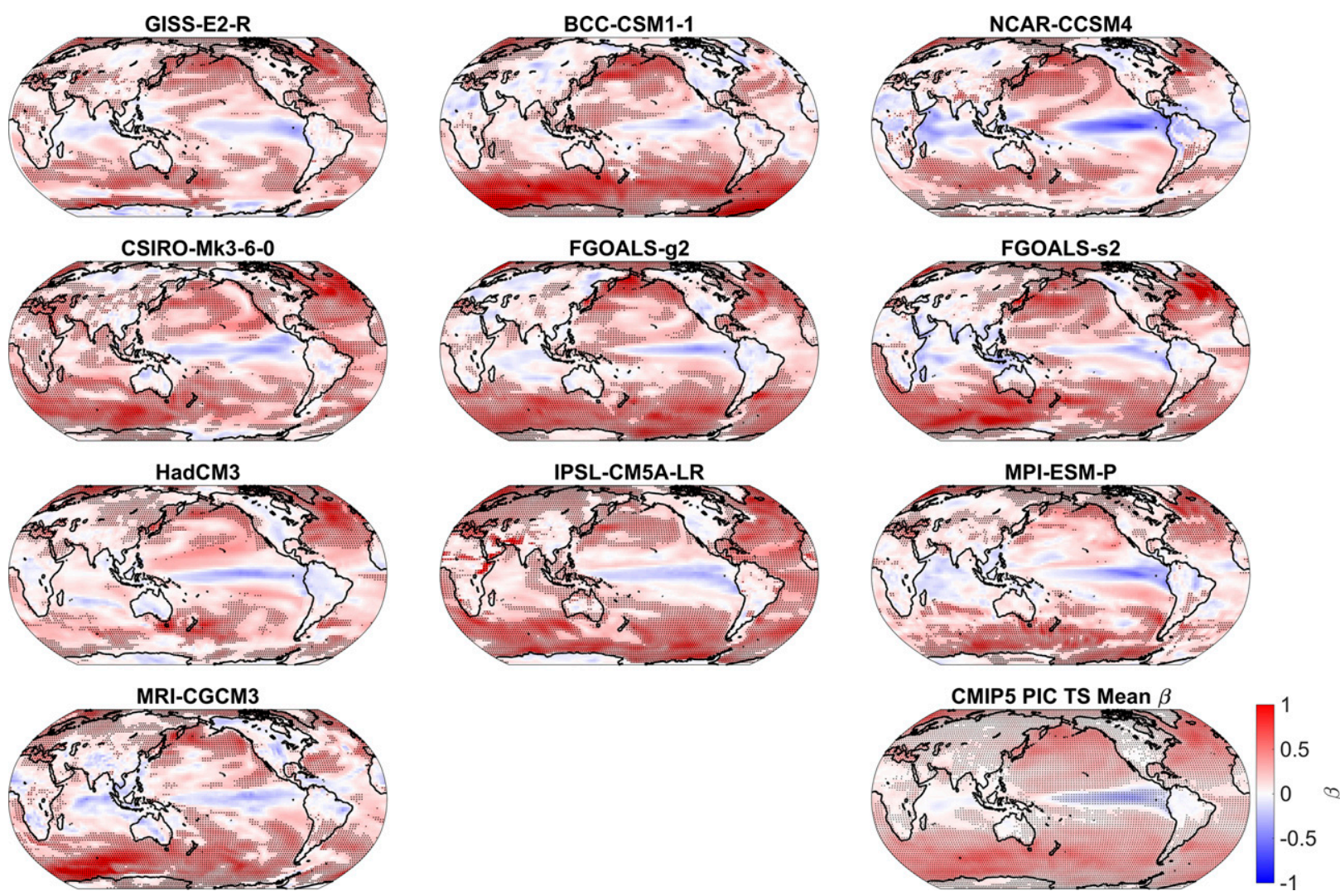

FIG. 4. Maps of surface temperature scaling $\beta$ from CMIP5 preindustrial control simulations that span at least $500 \mathrm{yr}$. Temperature $\beta$ maps from individual simulations are shown; (bottom right) the 26-member multimodel mean $\beta$ map is shown (blue to red shading indicates $\beta$ ). Here, we show the control $\beta$ maps for the individual models that conducted the last millennium experiment for better comparison to the CMIP5 LM mean map (Fig. 3). Stippling in individual run maps marks regions with $\beta$ values that fall outside $95 \%$ of $\operatorname{AR}(1)$ process $\beta$ values (see text for methods). Stippling in mean map marks regions where at least 20 out of 26 simulations agree on the sign of $\beta$ (remainder of PIC panels shown in the supplemental material).

\section{d. Coral data}

We compared CESM LME and CMIP5 temperature $\beta$ to a network of Indo-Pacific coral records. We selected all tropical Indian and Pacific Ocean centennial-scale coral records available from the Past Global Changes 2000 yr (PAGES 2k) network (Ahmed et al. 2013) and the NOAA paleoclimate coral data archive in the spring of 2016 (http://www.ncdc.noaa.gov/paleo/coral/coral_data. html). We excluded coral records with less than $100 \mathrm{yr}$ of continuous data to ensure our analysis would begin to resolve centennial-scale variability in our calculations of $\beta$ (see Table 2 coral record information). We first binned the monthly coral data into annual (January-December) mean bins, and then we calculated $\beta[(1 / 2)-(1 /$ record length frequencies)] for each (nondetrended) coral record. We shaded the coral $\beta$ in a circle using the same color bar as the model data at the corresponding latitude and longitude of the coral sample location (Fig. 8). If multiple coral records at least $100 \mathrm{yr}$ in length were available from the same location, we averaged their $\beta$ values before plotting. We chose to show the $\operatorname{coral} \beta$ on both model mean temperature and precipitation maps because these records can be sensitive to both sea surface temperatures and sea surface salinity; salinity often reflects changes in evaporation, precipitation, or runoff. We estimated values of coral-record $\beta$ across multiple frequency ranges $(1 / 2-1 / 500$ and $1 / 2-1 / 100 \mathrm{yr})$ and found that all coral records show some degree of power-law scaling across frequency ranges. Although each coral record's $\beta$ changes slightly if a new frequency range is selected, the mean $\beta$ of all coral sites effectively does not change between the two frequency ranges mentioned above. Additionally, we calculated $\beta$ for all pre-twentieth-century coral records with at least $100 \mathrm{yr}$ of data in this time period to test whether the low-frequency variability in coral records is solely an artifact of twentieth-century anthropogenic forcing. Although the pre-twentieth-century 


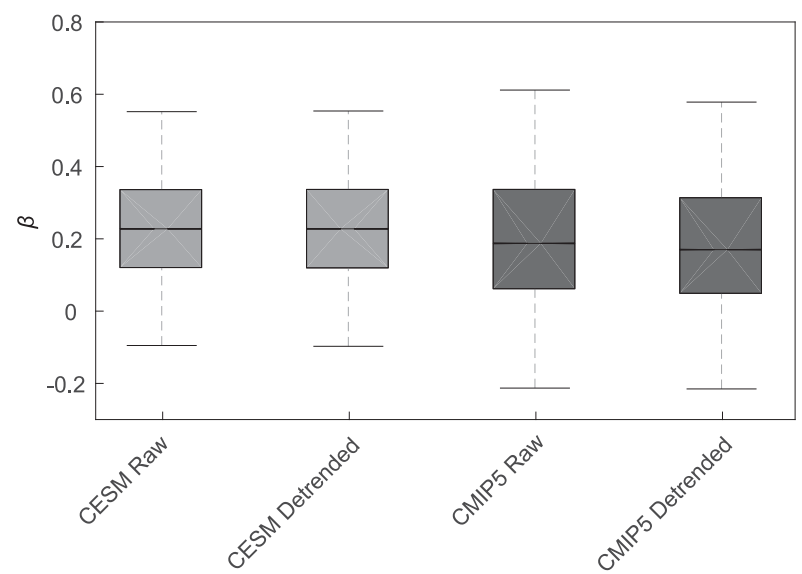

FIG. 5. Distribution of temperature values of $\beta$ for all grid boxes in the CESM LME and CMIP5 PIC models. Temperature values of $\beta$ calculated from raw normalized time series; linear trend removed from all normalized time series prior to calculation of $\beta$ in detrended time series.

$\beta$ value changed slightly for each coral record, we found a minimal difference in the mean $\beta$ of all the coral records (Table 2).

\section{e. Coral $\delta^{18} \mathrm{O}$ forward modeling}

We estimated spectra from observed proxy $\operatorname{coral} \delta^{18} \mathrm{O}$ and model-derived (NCAR CCSM4) "pseudocoral" $\delta^{18} \mathrm{O}$ at the PAGES $2 \mathrm{k}$ network coral sites (PAGES $2 \mathrm{k}$ $\delta^{18} \mathrm{O}$ records highlighted with bold font in Table 2). We used the Thompson et al. (2011) forward model, which applies a linear regression to combine temperature and salinity variability, to calculate forward-modeled pseudocoral $\delta^{18} \mathrm{O}$. We used the temperature and salinity data from the CCSM4 last millennium and historical simulations at the PAGES $2 \mathrm{k}$ network $\delta^{18} \mathrm{O}$ coral sites. For each coral site, we used the model data from the ocean grid box closest to the coral proxy site and the model data that overlapped temporally with the coral proxy data.

\section{f. Monte Carlo simulations of climate variability}

We used a Monte Carlo procedure to test if model $\beta$ values were significantly different than $\beta$ values generated by a simple autoregressive process. Here we are testing the null hypothesis grid point by grid point; in the climate system, there is a spatially coherent structure to variability, and we are not applying a multivariate approach to our analysis that takes into account the spatial autocorrelation in the climate system (Newman et al. 2016). We first generated 10000 time series with AR(1) set to the autocorrelation for each model grid box monthly time series (after removing the annual cycle). We then calculated the $\beta$ values for each of these time series (as with the actual data) to provide upper and lower confidence limits for AR(1) $\beta$ values (Fig. 9b). A simple autoregressive process can generate a wide range of $\beta$ values, but the $\operatorname{AR}(1)$ spectrum flattens at decadalmultidecadal scales, and a power-law fit is only a rough approximation of AR(1) scaling (Fig. 9) (Ault et al. 2013b). An AR(1) process with monthly lag-1 autocorrelation less than 0.6 typically generates a nearly flat spectrum, with $\beta$ values rarely greater than 0.2 (Fig. 9). The mean lag-1 autocorrelation of monthly temperature in CMIP5 is 0.56 $( \pm 0.27)$, whereas precipitation is essentially white noise with a lag-1 autocorrelation mean of $0.08( \pm 0.1)$.

\section{g. Global impacts of the temperature scaling in the Niño-3.4 region}

We compared simulated values of $\beta$ for Niño-3.4 SST to decadal-multidecadal drought frequency in El NiñoSouthern Oscillation (ENSO) teleconnected regions in CMIP5 LM. We calculated drought frequency using a "running mean method": we defined a drought as a unique instance when the 11- (decadal drought) or 35-yr (multidecadal drought) running mean of the normalized precipitation time series passed the -0.5 standard deviation threshold below the full time series mean (Ault et al. 2014). We then calculated the mean drought count (per century) over land for the following regions: western North America (WNA; $26^{\circ}-50^{\circ} \mathrm{N}, 125^{\circ}-100^{\circ} \mathrm{W}$ ), Australia (AUS; $40^{\circ}-10^{\circ} \mathrm{S}, 112^{\circ}-154^{\circ} \mathrm{E}$ ), northern Amazonia (AMAZ; $12^{\circ} \mathrm{S}-10^{\circ} \mathrm{N}, 70^{\circ}-35^{\circ} \mathrm{W}$ ), and the northern Middle East and central Asia (MIDEAST; $30^{\circ}-45^{\circ} \mathrm{N}, 35^{\circ}-70^{\circ} \mathrm{E}$ ). We picked these regions based on strong ENSO teleconnections in CMIP5 models and in observations.

We also compared tropical Pacific temperature variability to global temperature variability in CMIP5 LM. We calculated the mean temperature $\beta$ from all nontropical Pacific grid boxes and compared this average to the $\beta$ of the Niño-3.4 index. Additionally, we compared the mean simulated Niño-3.4 $\beta$ to the value of $\beta$ from the first mode of surface temperature variability in each CMIP5 LM model. We calculated the modes of variability after removing the linear trend from all grid boxes. We also tested the degree to which local temperature $\beta$ is related to the magnitude of the local ENSO teleconnection in the CESM LME control simulation; we calculated the local $r$ value of the ENSO temperature teleconnection and regressed the magnitude of this relationship with ENSO against the local temperature $\beta$ value.

\section{Results}

\section{a. Temperature}

We find that CMIP5 temperature spectral shapes (values of $\beta$ ) vary regionally (consistent with Henriksson et al. 2015; Fredriksen and Rypdal 2016). We observe the 


\section{a. Niño3.4}

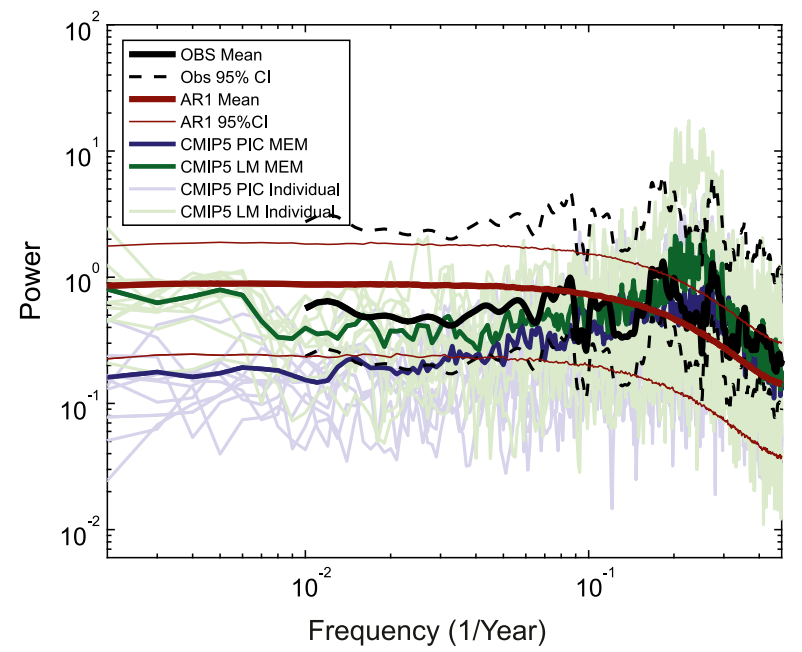

\section{c. South Atlantic}

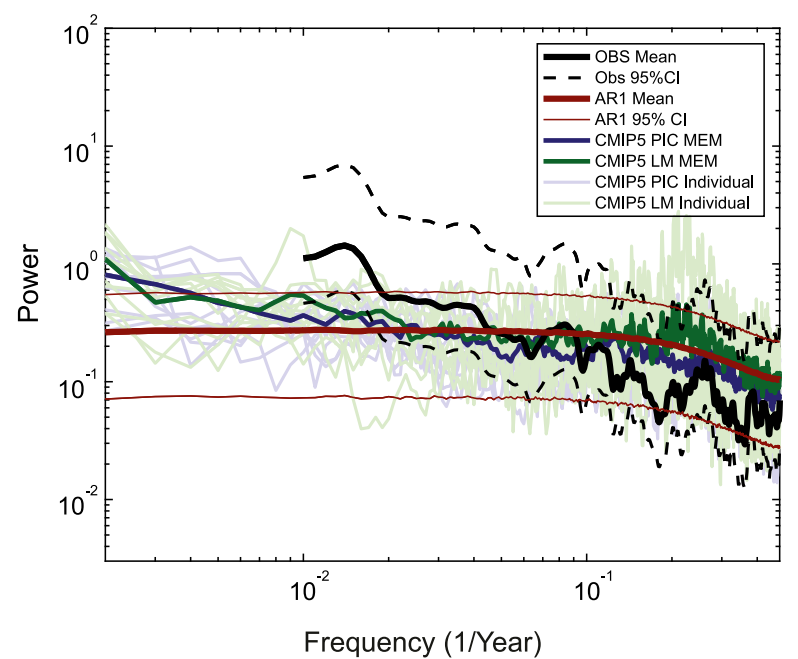

\section{b. North Atlantic}

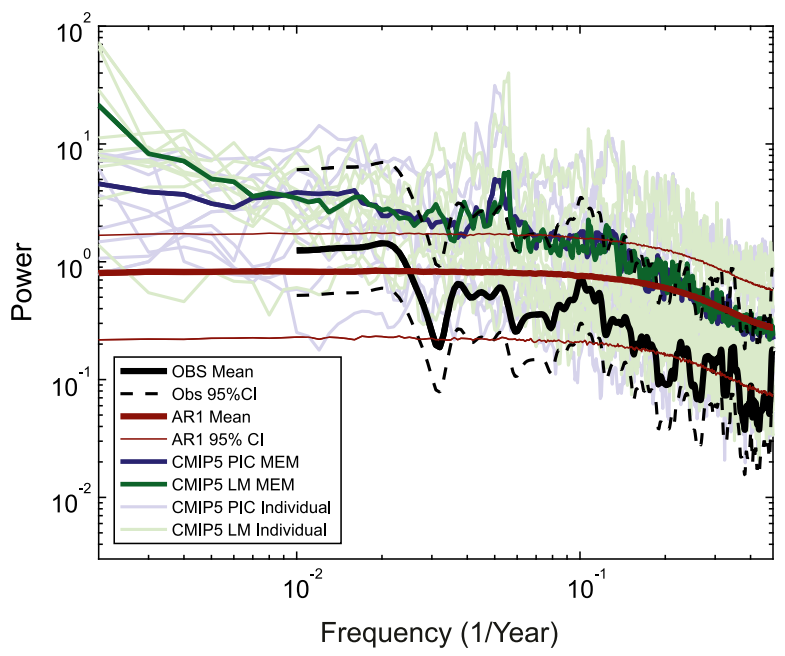

d. North Pacific

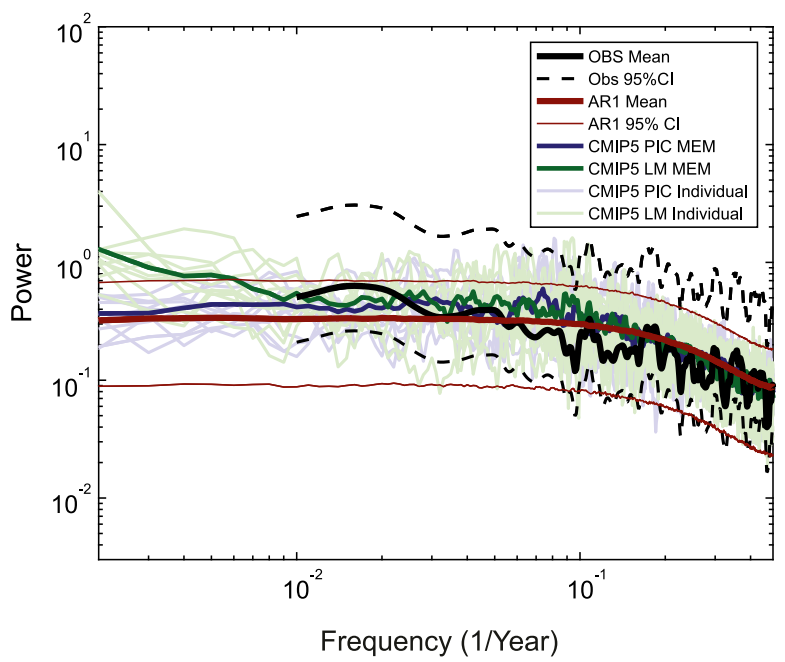

FIG. 6. Temperature spectra computed from CMIP5 and observations over four ocean regions. In all panels, the smooth dark red line shows the theoretical AR(1) spectrum for each region. CMIP5 LM simulations are shown in green and CMIP5 PIC shown in purple with thin lines showing the individual runs. Temperature spectra were averaged over the (a) Niño-3.4 $\left(5^{\circ} \mathrm{S}-5^{\circ} \mathrm{N}, 170^{\circ}-120^{\circ} \mathrm{W}\right)$, (b) North Atlantic $\left(45^{\circ}-55^{\circ} \mathrm{N}, 50^{\circ}-20^{\circ} \mathrm{W}\right)$, (c) South Atlantic $\left(50^{\circ}-40^{\circ} \mathrm{S}, 50^{\circ}-20^{\circ} \mathrm{W}\right)$, and (d) North Pacific $\left(20^{\circ}-40^{\circ} \mathrm{N}, 150^{\circ}-130^{\circ} \mathrm{W}\right)$ regions. Solid black lines indicate mean of observation spectra and dashed black lines outline minimum and maximum $95 \%$ confidence bounds of observation spectra. Thin brown lines outline Monte Carlo-derived upper and lower 95\% confidence bounds of AR(1) spectrum. The monthly autocorrelation values used to generate the $95 \%$ AR(1) confidence bounds in each ocean region are 0.88 (Niño-3.4), 0.81 (North Atlantic), 0.79 (South Atlantic), and 0.84 (North Pacific). We used a chi-squared approach to obtain the $95 \%$ confidence bounds of the observation spectra and show the minimum and maximum $95 \%$ confidence bounds among the four instrumental datasets in each panel. Note that time series used to estimate the power spectra for this figure were not normalized prior to spectral estimation for better comparison across datasets.

lowest temperature $\beta$ values in the tropics and the highest $\beta$ values over mid- and high-latitude oceans (Figs. 2-4). CMIP5 temperature spectra in the tropical Pacific tend to have the most power at interannual frequencies, whereas over higher-latitude oceans the temperature spectra exhibit more power at lower frequencies (Fig. 6) (Fredriksen and Rypdal 2016). Although the tropical
Pacific and Indian Oceans appear to be blue, the spectral shape in these regions is not appropriately described by a linear fit due to the large interannual variance peak (Figs. 1d and 2; consistent with Henriksson et al. 2015; Fredriksen and Rypdal 2016).

Last millennium and control simulations show similar patterns. In CESM LME, temperature values of $\beta$ are 


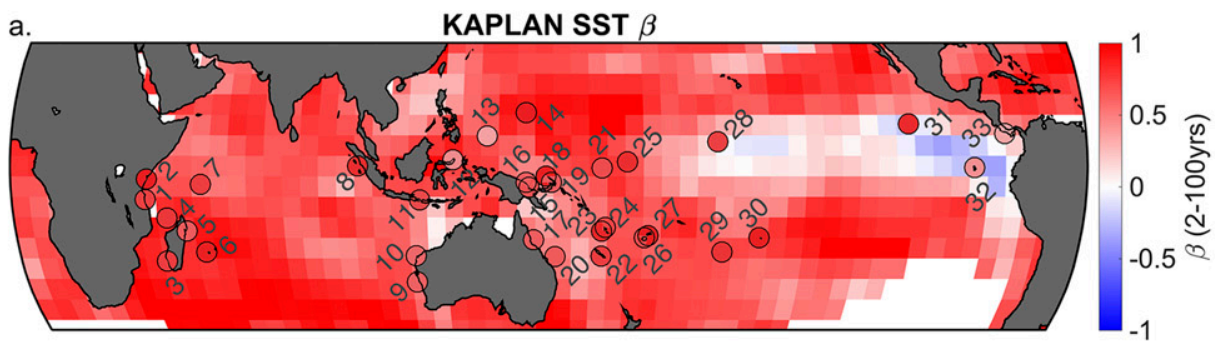

b. Temperature Observation and CMIP5 Hist. $\beta$ Distribution at Coral Sites (1850-2015 CE)

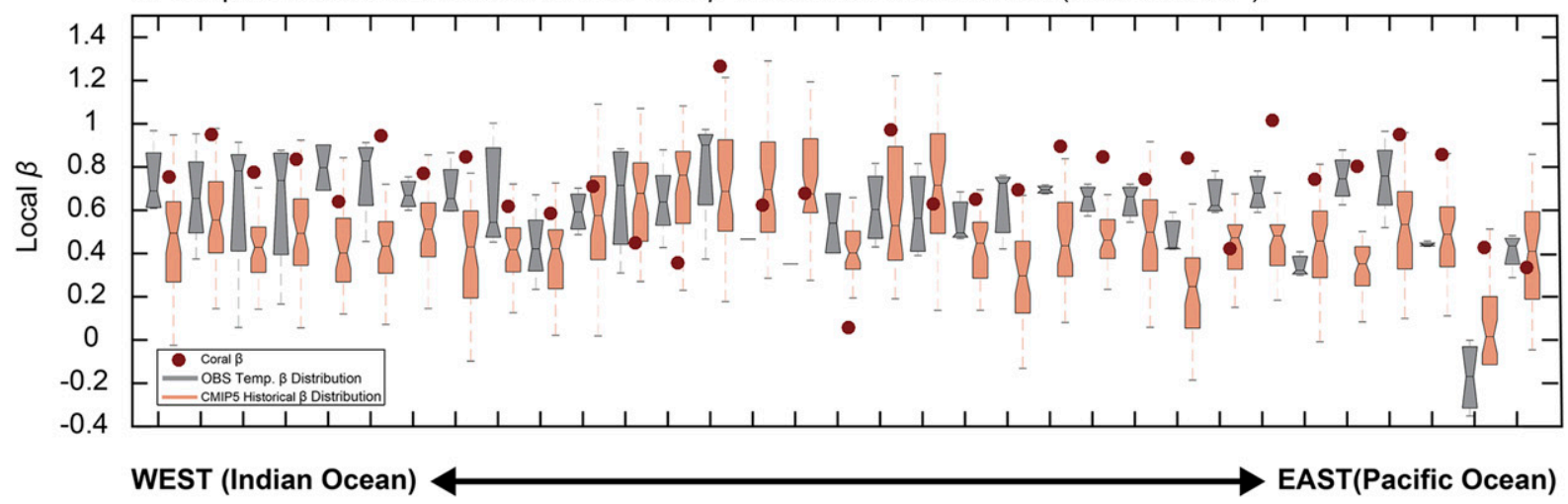

C. CMIP5 LM (850-1850) and CMIP5 HIST (1850-2005) Surface Temperature $\beta$ Distribution at Coral Sites

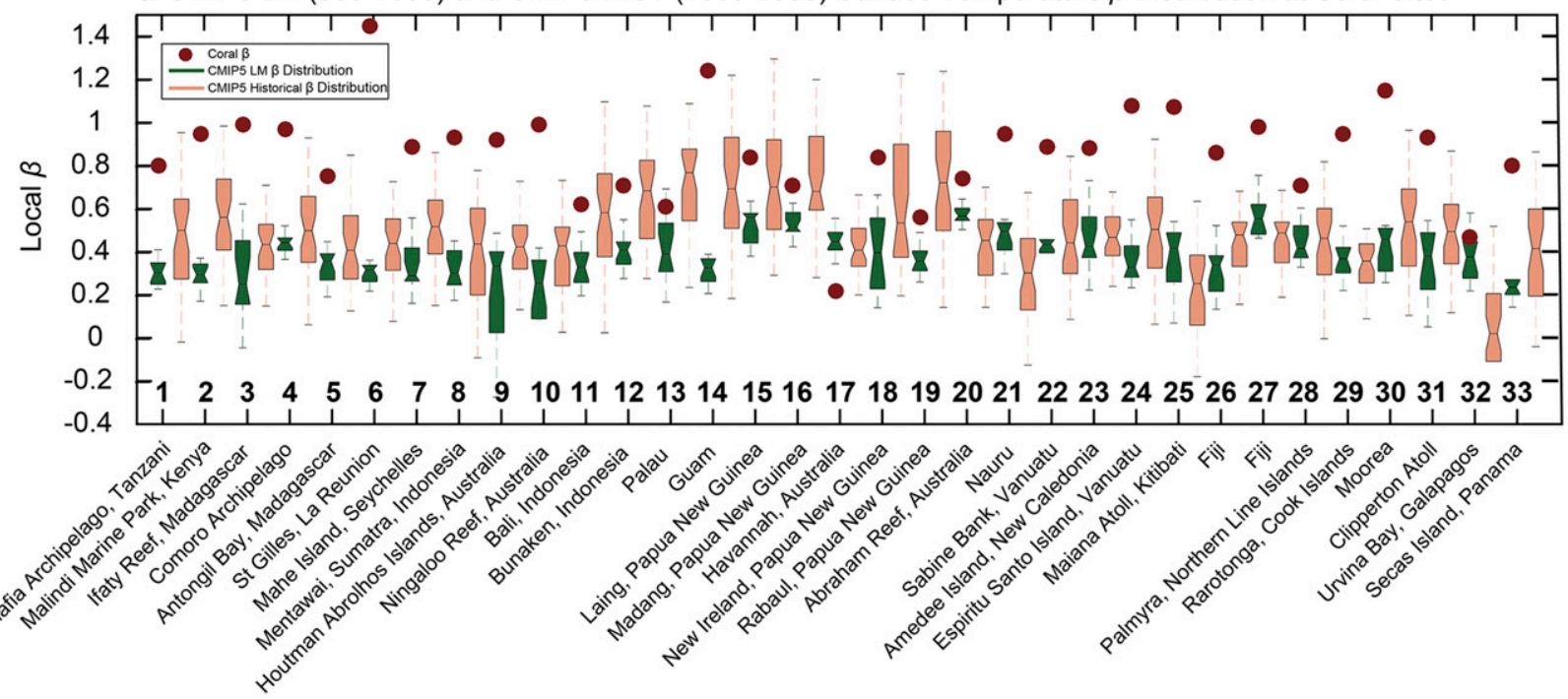

FIG. 7. Map of coral locations and distribution of temperature values of $\beta$ at coral locations by longitude, from west to east. Values of $\beta$ in corals (dark red circles), observations (gray boxplots), CMIP5 historical simulations (orange boxplots), and CMIP5 LM simulations (green boxplots). (a) Map of instrumental era (Kaplan SST data, 1856-2014 CE) temperature values of $\beta$ and nineteenth- to twentiethcentury coral $\beta$ mapped on the same color scale. (b) Historical era (1850-2015 CE) temperature values of $\beta$ at coral locations calculated from gridded observation datasets, coral records, and CMIP5 historical runs (1850-2005 CE). (c) Temperature values of $\beta$ at the same locations calculated from CMIP5 LM (850-1850 CE) simulations, coral records (calculation of $\beta$ from full paleoclimate record length), and CMIP5 historical runs (1850-2015 CE). Numbers in (c) correspond to coral locations on map in (a). Temperature values of $\beta$ calculated between 1/2- and 1/100-yr frequencies on time series without removing trend. We used three data products (HadISST, Kaplan SST, and NOAA ERSSTv4) to calculate $\beta$, all of which use EOF-based methods to fill in missing data among observations that are increasingly sparse before the late twentieth century (see data and methods). 


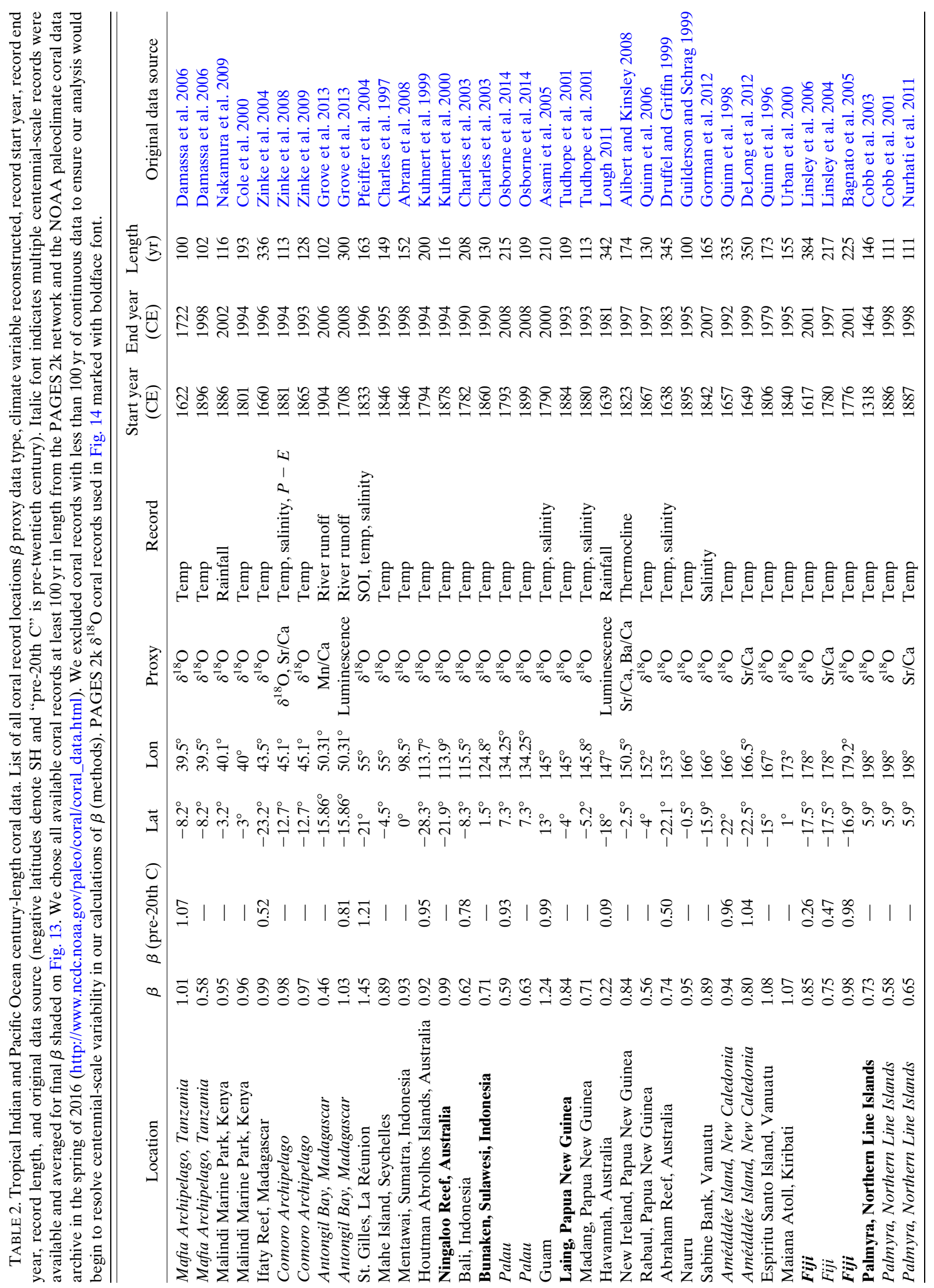




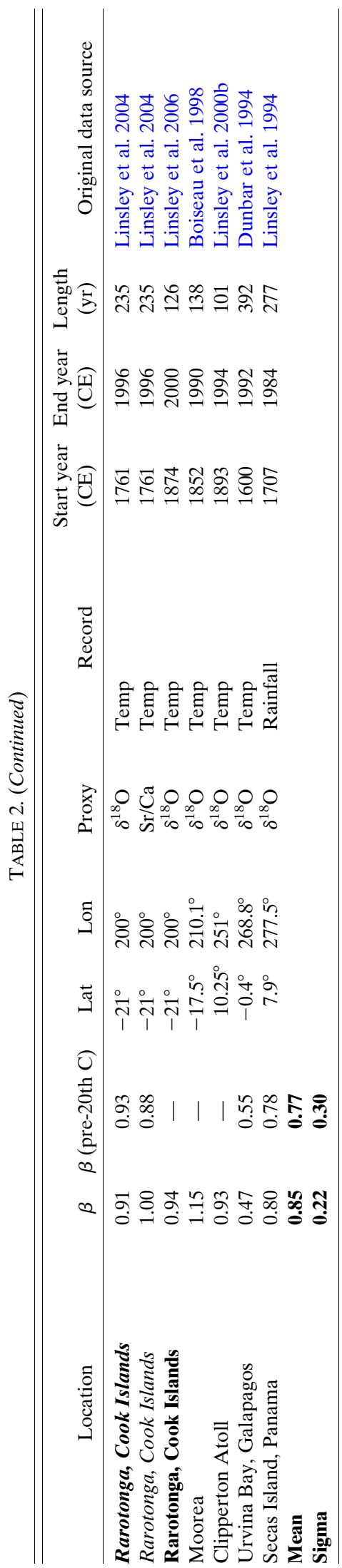

typically positive across the globe, except in the tropical Pacific and Indian Oceans and in some parts of the Southern Ocean (Fig. 2). CMIP5 LM temperature values of $\beta$ are also positive across the globe except in the tropical Pacific and some regions in the Southern Ocean in certain models (Fig. 3). CMIP5 PIC temperature values of $\beta$ are slightly lower than CMIP5 LM values, but the spatial patterns remain consistent between the LM and PIC forcing, with the highest values at higher latitudes over the oceans and lower values near the tropics (Figs. 4 and 10).

\section{b. Precipitation}

Simulated temperature values of $\beta$ exhibit both higher amplitudes (positive and negative) and greater consistency in the sign of $\beta$ than precipitation $\beta$ across models and experiments (Figs. 11-13). Simulated precipitation is nearly white at most locations across the globe (Fig. 1e), and the sign of precipitation $\beta$ is much more variable than the sign of temperature $\beta$ (Fig. 1f), even among different ensemble members of the same model with identical forcing (Fig. 11). However, the sign of CMIP5 precipitation $\beta$ tends to loosely follow the sign of temperature $\beta$; the tropical Pacific tends to have low values of $\beta$ for both variables (Figs. 1d,f), and many regions over high-latitude oceans are consistently slightly red for both variables (Fig. 10).

In CESM LME, there is agreement among different ensemble members that precipitation spectra over the Indian Ocean, the central and eastern tropical Pacific, and land in the tropics are dominated by interannual variability. By contrast, precipitation spectra over the farwestern tropical Pacific, isolated patches of the South and North Pacific gyres, North Atlantic, and Southern Ocean regions are all slightly red in CESM LME (Fig. 11). CMIP5 LM models also show that precipitation $\beta$ values are low over the tropical Pacific and slightly positive over much of the Atlantic Ocean and polar oceans (Fig. 12). Similarly, many CMIP5 PIC models agree that precipitation is dominated by interannual variability in the tropical Pacific and by lowfrequency variability over the high-latitude oceans (Fig. 13). The largest disagreement among different models, in terms of the magnitude of precipitation $\beta$, is in the North Atlantic (Figs. 14d,f).

\section{c. Testing against an AR(1) null hypothesis}

Some degree of redness in the climate system may arise from ocean damping of weather noise (Hasselmann 1976; Newman et al. 2003, 2016). Here we evaluate the magnitude of CMIP5 $\beta$ values against the null hypothesis that increasing variability with time scale is generated exclusively from smoothing of 

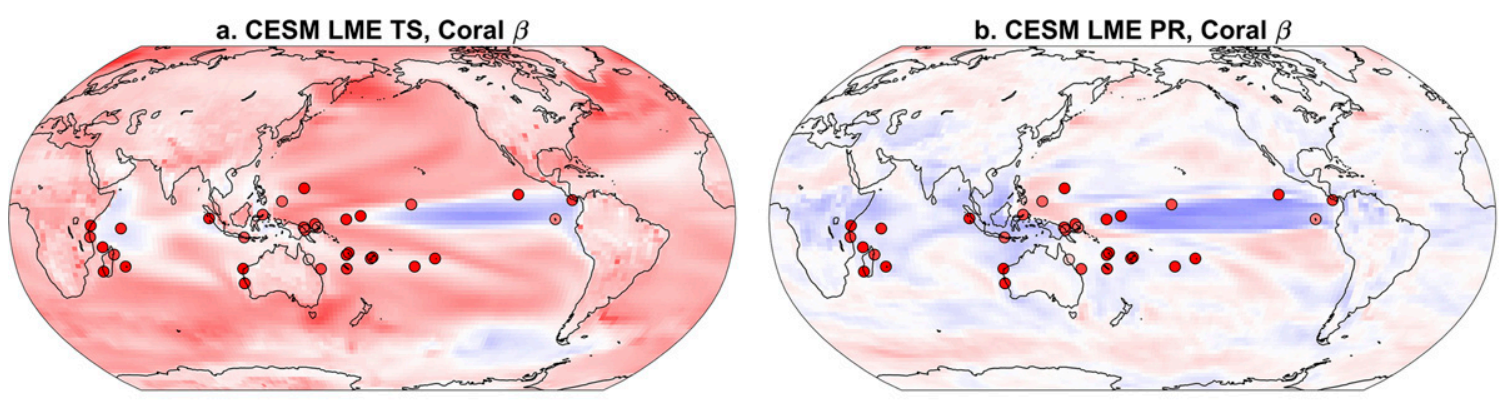

c. CMIP5 LM TS, Coral $\beta$
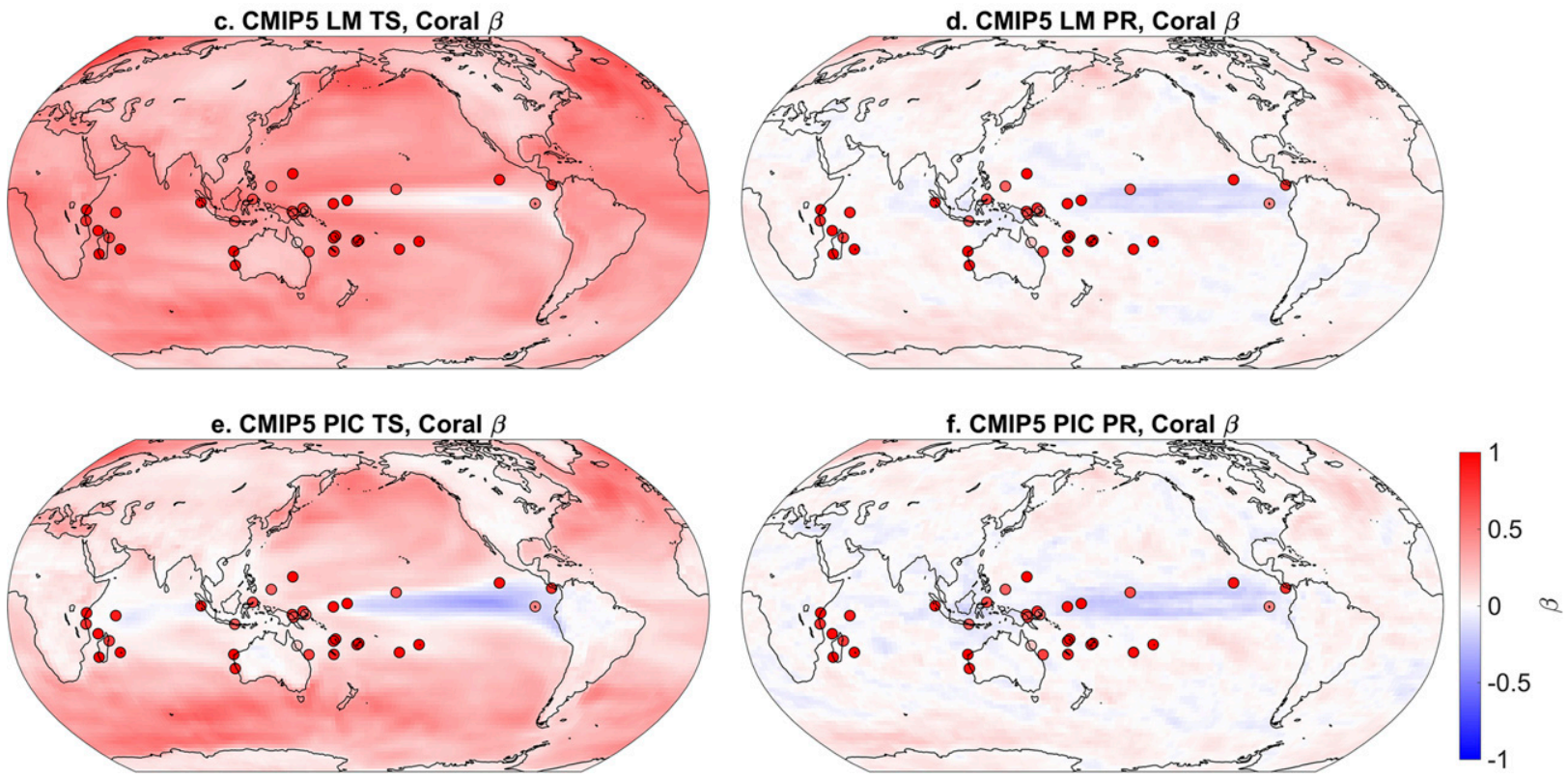

FIG. 8. CMIP5 multimodel mean scaling compared to tropical Indian and Pacific Ocean coral scaling $\beta$. Colors indicate $\beta$ values for annual (left) annual surface temperature and (right) precipitation of (a),(b) 10 all-forcing simulations of NCAR CESM LME, (c),(d) 10 all-forcing CMIP5 LM simulations, and (e),(f) 10 CMIP5 PIC simulations. The shaded dots represent the locations and $\beta$ values of tropical Pacific and Indian Ocean coral records (same color bar as mapped model $\beta$ ).

high-frequency forcing. We find that CMIP5 temperature $\beta$ values are distinct from $\beta$ values generated by a simple autocorrelated $[\mathrm{AR}(1)]$ process over most of the high-latitude oceans and continents, where temperature $\beta$ values exceed $\sim 0.15$ (Figs. $2-4$ ). However, over much of the central and eastern tropical Pacific and Southern Oceans, CMIP5 LM models do not generate temperature $\beta$ values distinct from $\operatorname{AR}(1)$ $\beta$ values. The low-latitude area with low $\beta$ values expands in unforced CMIP5 models; most CMIP5 PIC models do not generate $\beta$ values distinct from $\beta$ values generated by an $\mathrm{AR}(1)$ process across most of the tropics. In fact, much of the midlatitude temperature variability in many CMIP5 PIC models is difficult to distinguish from variability generated by an $\mathrm{AR}(1)$ process (Fig. 4).

Our results indicate that most CMIP5 models generate temperature variability distinct from monthly autocorrelation over high-latitude oceans (Fig. 6) (Manabe and Stouffer 1996). These model-based results support the assertion that Hasselmann-type processes can explain much of CMIP5 models' unforced temperature behavior over low-to-midlatitude oceans (Hasselmann 1976; Manabe and Stouffer 1996; Ault et al. 2013a). However, although an AR(1) process can generate $\beta$ values that are similar in magnitude to the tropical Pacific CMIP5 temperature $\beta$ values, the shape of the spectrum in the cold tongue region differs from an AR(1) spectrum in many CMIP5 models (Fig. 6a). Although there is some degree of surface ocean memory process (lag-1 monthly autocorrelation of $\sim 0.88$ ) in the tropical Pacific, the mechanisms that generate interannual variability include well-described coupled oceanatmosphere interactions (e.g., Zebiak and Cane 1987), and an AR(2) model more accurately describes this variability (e.g., Neumaier and Schneider 2001). 

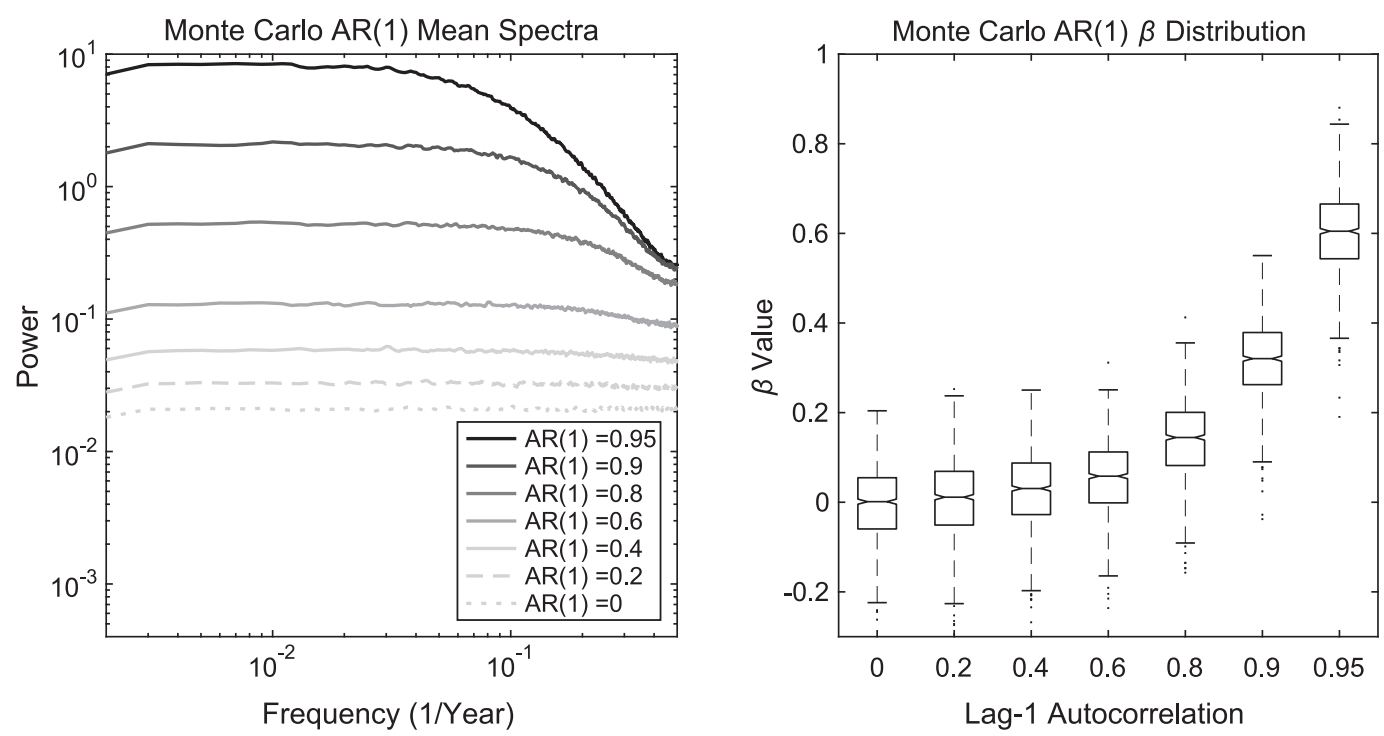

FIG. 9. AR(1) spectra and $\beta$ value distributions. Examples of (left) mean AR(1) spectra and (right) associated $\beta$ value distributions to illustrate the effect of different monthly lag-1 autocorrelations on the spectrum of variability and associated $\beta$ values. Mean spectra were calculated from 10000 iterations of each AR(1) process.

Most CMIP5 models generate precipitation variability that falls outside the variability expected from a simple autocorrelated process in isolated midlatitude and high-latitude regions (Figs. 11-13). However, not all CMIP5 models show this behavior in the same geographic locations, even among different ensemble members of the same model (Fig. 11). We find that $\sim 15 \%$ of all CMIP5 LM and PIC precipitation $\beta$ values fall outside the $95 \%$ confidence interval (greater than the statistically expected $5 \%$ and far less than the $\sim 75 \%$ of grid boxes for simulated TS in CMIP5 LM). Based on these results, we suggest simulated precipitation variability is effectively white in most geographic locations, but local ocean-atmosphere coupling or other climate variability can influence precipitation $\beta$. For example, in the tropical Pacific where sea surface temperature and precipitation tend to be coupled, interannual variance dominates the spectrum in both temperature and precipitation (Figs. 1d,f). However, in other regions with low-frequency temperature variability, precipitation variability remains white (Figs. 1c,e).

\section{d. Coral comparison}

CMIP5 models generally show that the variance spectra of central and eastern tropical Pacific temperature and precipitation are white or dominated by interannual variability (Figs. 1, 2-4, and 11-13). However, when we estimate $\beta$ from coral paleoclimate records across the tropical Indo-Pacific Oceans, we find that none of these records reproduce this spectral pattern (Fig. 8). All of the coral records analyzed here show red spectra, and there is no interannual variance peak dominating the spectrum or disrupting the continuum of variability. In fact, all coral records we analyze suggest power-law scaling behavior in the tropical Pacific and Indian Oceans (mean coral $\beta=0.85 \pm 0.23$ ). This finding is consistent regardless of our use of temperature-, precipitation-, or salinity-sensitive coral records or of our use of skeletal $\delta^{18} \mathrm{O}, \mathrm{Sr} / \mathrm{Ca}$, or luminescence records. In other words, these high values of tropical Pacific and Indian Ocean coral $\beta$ are robust regardless of coral record type or location, suggesting that either CMIP5 models tend to underestimate the magnitude of $\beta$ in this region or that corals are incorporating a nonclimatic red noise signal.

\section{e. External forcing in CMIP5 LM}

External forcings used in the CESM LME experiments include orbital, well-mixed greenhouse gases, land use and land cover, volcanic forcing of stratospheric aerosols, and solar variations (Schmidt et al. 2012). We compare the impact of preindustrial era forcing on $\beta$ in the CESM LME and find greenhouse gas, land-use and land-cover, orbital, and solar variability have minimal impacts on LM variance distributions (Fig. 15). The volcanic-only forcing in the CESM LME is the only external forcing that appreciably increases $\beta$ values in simulated temperature (Fig. 15b). This volcanically forced increase in temperature $\beta$ is particularly strong in the tropics in CESM (land only) and in GISS-E2-R (land and ocean) (Figs. 10 and 16). We observe a similar signal when we compare the CMIP5 LM (all forcing, including volcanic forcing) and CMIP5 PIC simulations: a large 


\section{a. GISS,CESM TS Volc/Non}

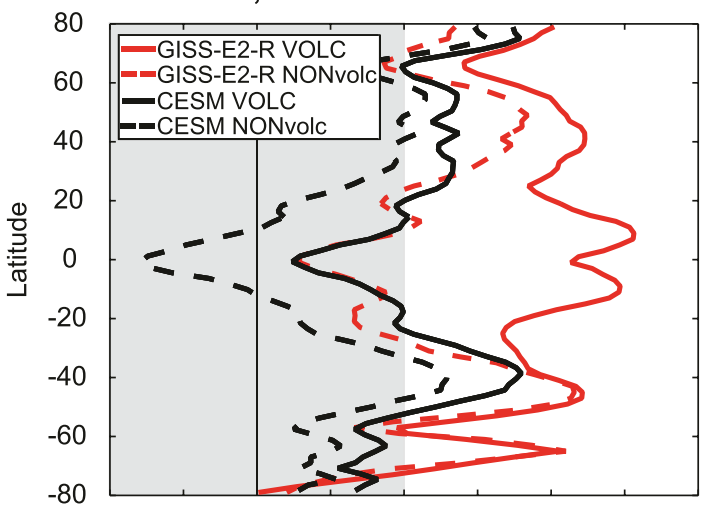

c. CMIP5 LM, PIC, CESM TS

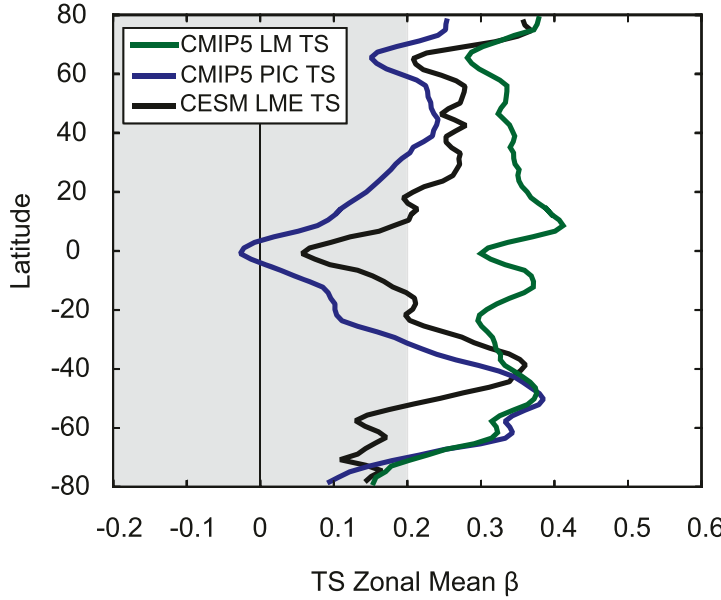

b. GISS,CESM PR Volc/Non

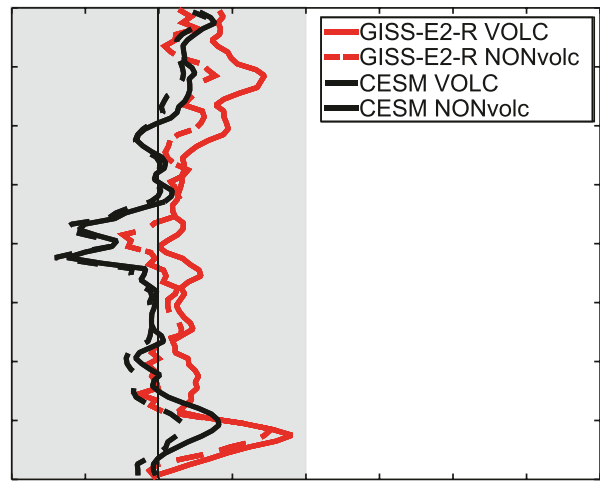

d. CMIP5 LM, PIC, CESM PR

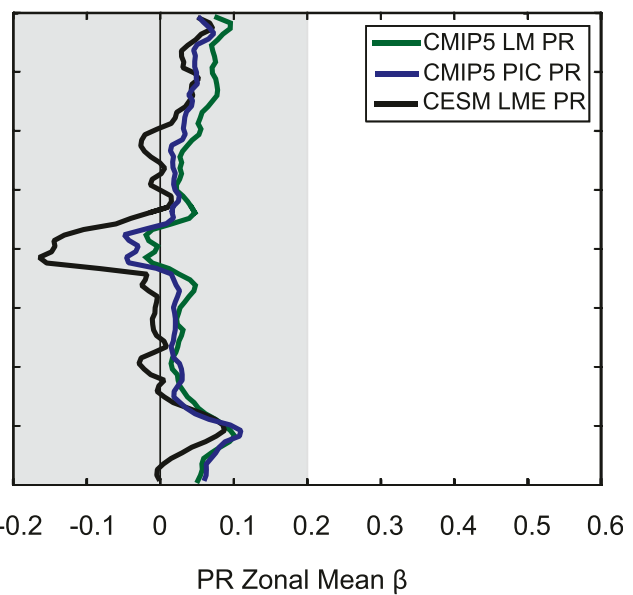

FIG. 10. CMIP5 zonal mean temperature and precipitation scaling $\beta$. Zonal mean (a) surface temperature and (b) precipitation $\beta$ in NCAR CESM last millennium ensemble (black) and NASA GISS-E2-R last millennium (red) in volcanically forced simulations (solid lines) and non-volcanically forced simulations (dashed lines). Zonal mean (c) surface temperature and (d) precipitation $\beta$ values in CESM LME (all forcing only, black lines), CMIP5 LM (green lines), and CMIP5 PIC (blue lines). Note black vertical line marks mean white noise spectral slope, and gray outline delineates $\beta$ values that are indistinguishable from white noise (lag-1 autocorrelation of zero) from Fig. 9.

increase in temperature $\beta$, particularly over the tropics (Figs. 8c, 8e, and 10c). Although volcanic forcing impacts the temperature spectrum in CESM and GISSE2-R, external, preindustrial forcing has little impact on the modeled precipitation spectrum (Figs. 8d, $8 \mathrm{f}$, and 10d). Precipitation $\beta$ values in volcanically forced CMIP5 simulations are only slightly higher than $\beta$ values in unforced CMIP5 simulations (Figs. 10, 12, and 13).

\section{Discussion}

We provide an overview of temperature and precipitation scaling in multicentury simulations of the latest (CMIP5/IPCC AR5) Earth system models, under both unforced and pre-industrially forced conditions.
Similar to Fredriksen and Rypdal (2016), we find that temperature scaling in these models is highly variable regionally, particularly weak over the tropical IndoPacific, and stronger over the high-latitude oceans. Precipitation scaling is similarly weak over much of the tropical Indo-Pacific and is dominated largely by interannual variability in the central and eastern tropical Pacific. We focus on the tropical Indo-Pacific for data-model comparison, where corals provide an unusually widespread and unsmoothed paleoclimate record that indicates consistently strong power-law (red) behavior. Preindustrial external forcing is insufficient to bring model and paleodata results into agreement for decadal and longer variability estimates. Here we address specific issues raised by these discrepancies. 

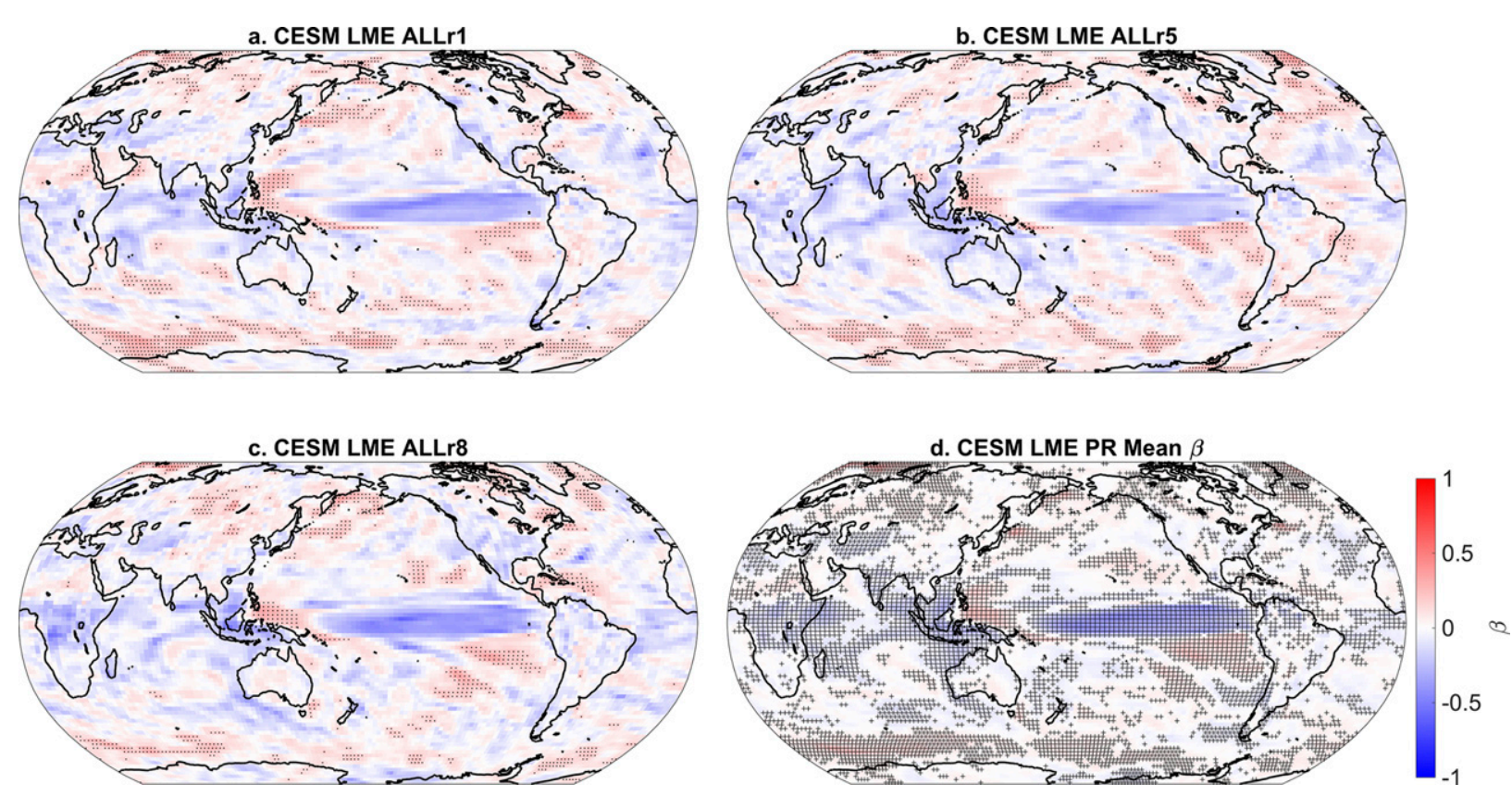

FIG. 11. As in Fig. 2, but for precipitation and no vertical hatching where power-law behavior $\beta$ is a poor fit.

\section{a. Intermodel variance disagreements in CMIP5}

Among different CMIP5 models, we see large differences in the magnitudes of temperature $\beta$. These disagreements are regionally focused, with the largest differences in the Southern, tropical Pacific, and North Atlantic Oceans (Fig. 14). Although we removed CMIP5 models with large global temperature drifts from our analysis, local climate drift over the Southern Ocean could contribute to temperature $\beta$ disagreement in this region (Sen Gupta et al. 2013). Additionally, this disagreement could be due to internal variability in climate behavior; the length of the model runs $(500+y r)$ may not capture the full spectrum of variance (e.g., Wittenberg 2009). Disagreement among models could also result from differences in how internal variability is modeled in key parts of the global climate system [e.g., Atlantic overturning circulation (MacMartin et al. 2013), Southern Ocean circulation (Russell et al. 2006), and Pacific dynamics (Bellenger et al. 2014)].

The largest magnitude of precipitation $\beta$ disagreement among different models is in the North Atlantic (Fig. 14). This disagreement could be due to the differences in the simulation of Atlantic overturning circulation among CMIP5 models (MacMartin et al. 2013) and the impact of differing local low-frequency temperature variability on the precipitation spectrum. Models that tend to have high temperature $\beta$ in the
North Atlantic also tend to have high precipitation $\beta$ $(r=0.74)$.

\section{b. Possible causes of scaling behavior over high-latitude oceans}

Our results indicate that most CMIP5 models generate temperature variability distinct from monthly autocorrelation over high-latitude oceans (Fig. 6) (Manabe and Stouffer 1996). Although ocean circulation and coupled dynamics are prime candidates for generating low-frequency variability in CMIP5 models, scaling behavior can be present in high-latitude oceans even without fully coupled, complex deep ocean circulation. For example, Barsugli and Battisti (1998) find that coupling between the atmosphere and ocean can explain the increase in low-frequency variability observed in Manabe and Stouffer (1996), even in the absence of oceanic circulation. Studies have also shown that adding deeper ocean circulation and various mixed layer depths to the simple Hasselmann (1976) model can increase low-frequency variability (e.g., Fraedrich et al. 2004; Barsugli and Battisti 1998; Frankignoul and Hasselmann 1977; Lemke 1977). Therefore, although CMIP5 temperature $\beta$ over the high-latitude oceans may not be consistent with a simple Hasselmann-type model, this apparent increase in low-frequency variability with time scale may be consistent with a two-layer Hasselmann-type model with atmospheric forcing (e.g., Fraedrich et al. 2004). 

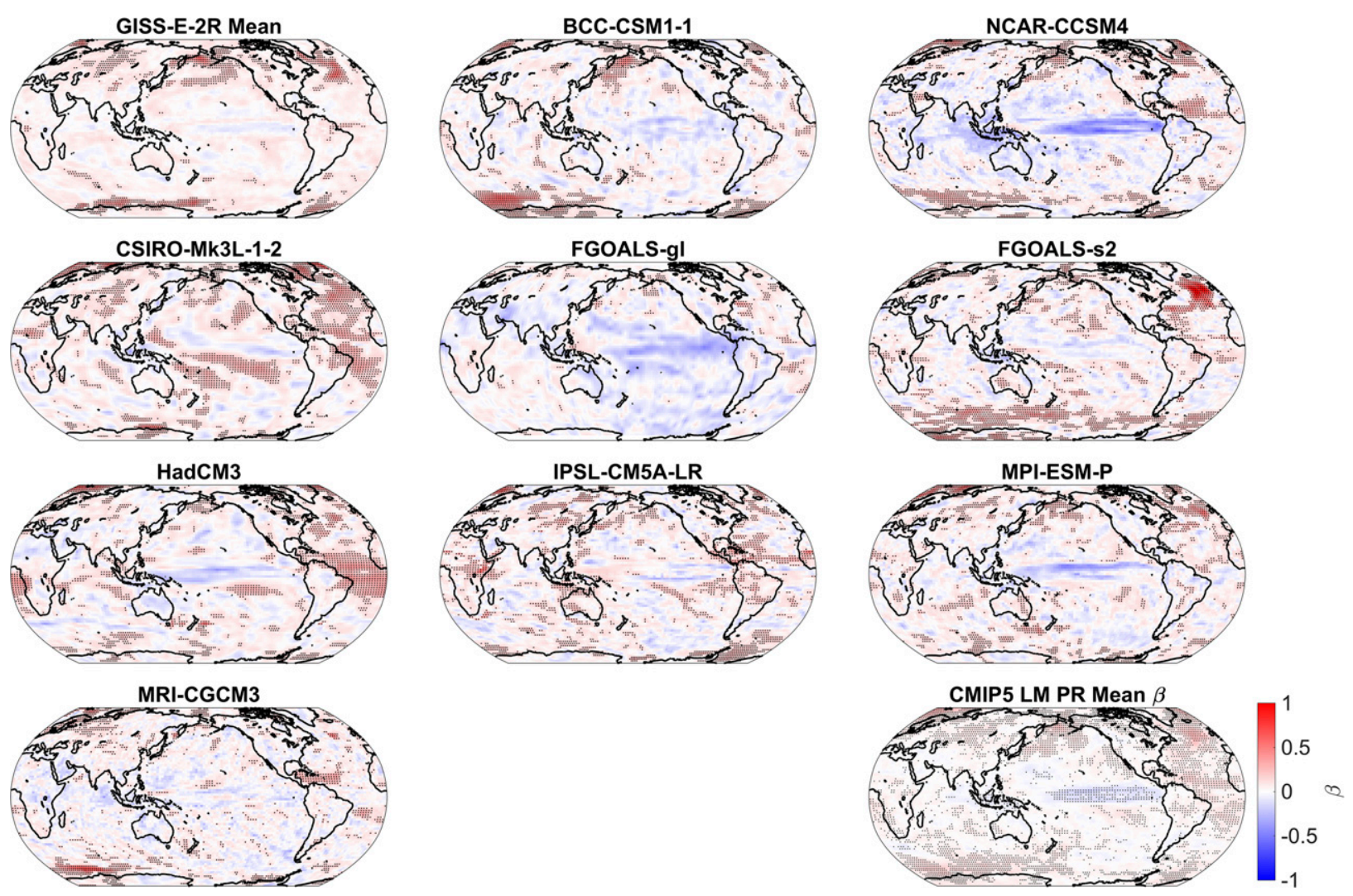

FIG. 12. As in Fig. 3, but for precipitation.

\section{c. Discrepancies among variance estimates in models, proxies, and instrumental observations}

The coral records analyzed here indicate power-law scaling behavior across the tropical Pacific and Indian Oceans, but the instrumental record $\beta$ does not always agree with historical-era coral $\beta$ (Figs. 7a,b). Coral and instrumental records tend to agree that low-frequency variability defines the temperature spectrum across much of this region. However, instrumental records show no such behavior in the cold tongue region of the eastern equatorial Pacific (Fig. 7a), and CMIP5 spectra agree quite well with the short observation record (Fig. 6a). The two coral records in or near this region (Galapagos and Palmyra) show stronger scaling than the instrumental record (Fig. 7a). Yet the observation record of tropical Pacific temperatures is extremely sparse as recently as $1955 \mathrm{CE}$, and the record loses consistent coverage before 1975 CE (e.g., Fairbanks et al. 1997; Deser et al. 2010). Furthermore, these statistically infilled instrumental data depend on stationary relationships between poorly and better-observed ocean regions and therefore may not accurately resolve multidecadalcentennial-scale spectral estimates. Additionally, different sea surface temperature (SST) datasets disagree on the magnitude of long-term trend in the Pacific and thus may disagree on low-frequency variability estimates (Deser et al. 2010). The observation record therefore cannot rule out low-frequency climate variability in the tropical Pacific.

Paleoclimate records show that the magnitude of ENSO variance has changed throughout the Holocene (e.g., Cobb et al. 2013; McGregor et al. 2013), and multicentury coral records indicate that decadal-scale tropical Pacific variability was stronger before the midtwentieth century (Damassa et al. 2006; Ault et al. 2009). Similarly, long climate model simulations show intervals of stronger and weaker interannual ENSO variability (e.g., Wittenberg 2009). However, lower-frequency variability in both temperature and precipitation appears considerably different in CMIP5 models (weak) as compared to paleoclimate data (strong) (Fig. 8).

We further examine the coral-CMIP5 tropical temperature spectral discrepancies by forward modeling coral $\delta^{18} \mathrm{O}$ at the PAGES $2 \mathrm{k}$ network $\delta^{18} \mathrm{O}$ coral sites, using SST and salinity from the historical and last millennium CCSM4 simulations to create pseudocoral records (Thompson et al. 2011). We find a general agreement in interannual-decadal pseudocoral and observed coral $\delta^{18} \mathrm{O}$ variability. However, observed coral 

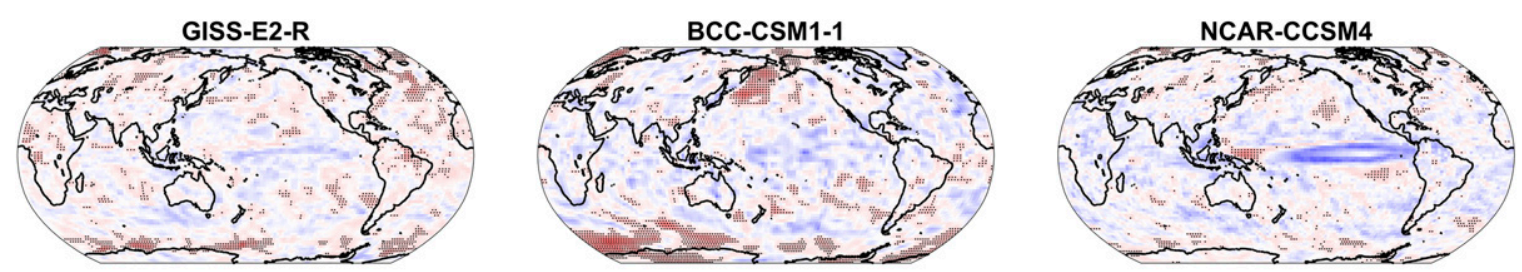

CSIRO-Mk3-6-0
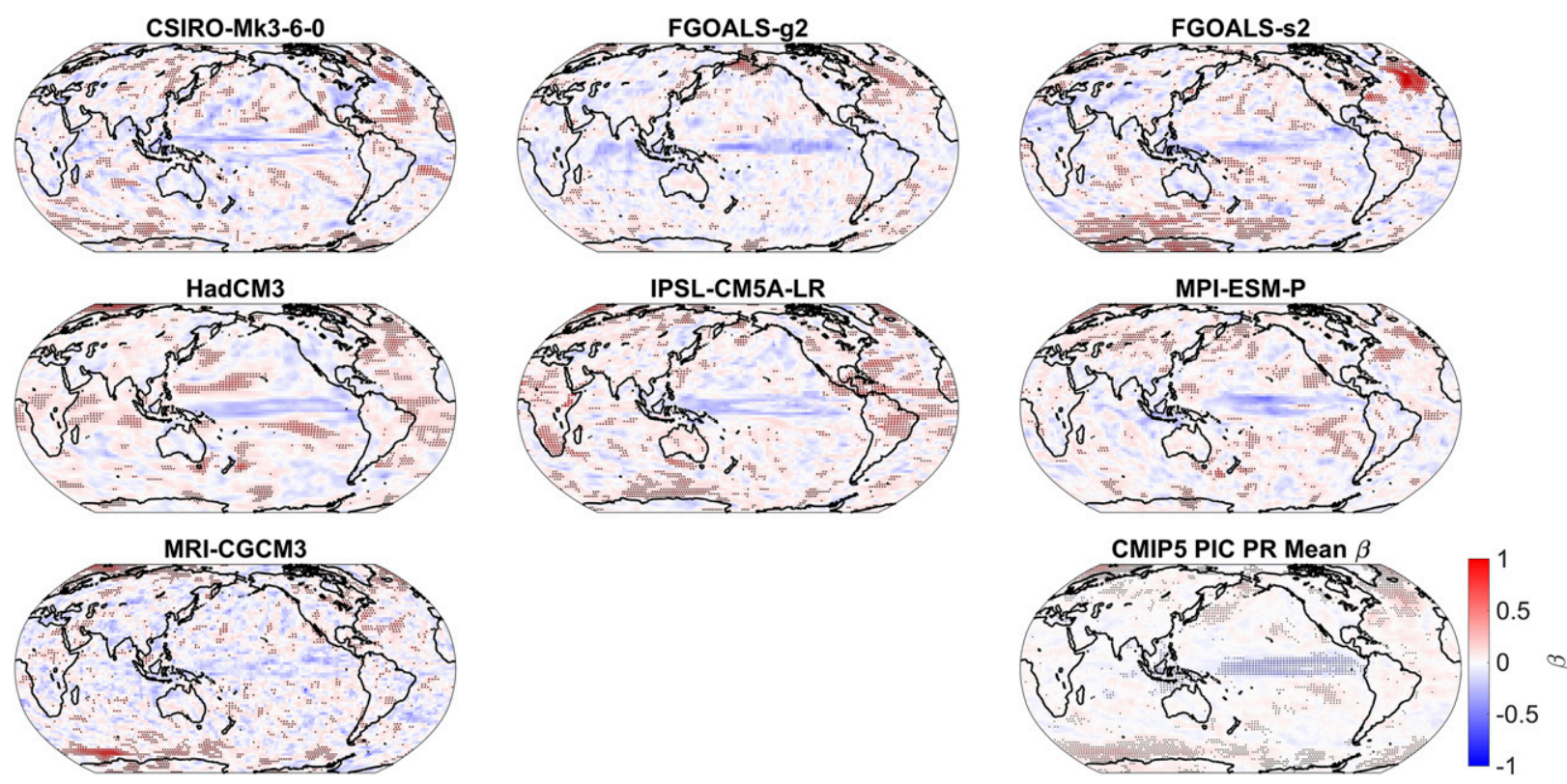

FIG. 13 As in Fig. 4, but for precipitation.

$\delta^{18} \mathrm{O}$ shows more variance at multidecadal-century time scales than pseudocoral $\delta^{18} \mathrm{O}$ (Fig. 17). Similarly, the interannual instrumental temperature variance at these sites agrees well with CCSM4 SST variance, but the model and mean instrumental spectra begin to deviate at multidecadal time scales. However, the least variable of the observation-based data products (HadISST and Kaplan SST) agrees with multidecadal temperature variability in CCSM4 (Fig. 17).

Outside the tropics, CMIP5 models and instrumental observations agree that temperature variance increases with time scale (Fig. 6). However, even if the overall shape of the instrumental and the simulated spectra are similar, many models are considerably more variable than the instrumental record across the spectrum in regions such as the North Atlantic (Fig. 6b) (Laepple and Huybers 2014a). In other regions, such as the South Atlantic, many models overestimate interannual variability and underestimate multidecadal variability (Fig. 6c) (Laepple and Huybers 2014a).

\section{d. Possible explanations for proxy-model mismatch}

Possible reasons for the proxy-model mismatch include biases in paleoclimate proxies, shortcomings in
Earth system models, and uncertainties in the last millennium forcing reconstructions (Schmidt et al. 2012). Potential model shortcomings include insufficient energy cascades in models (Ferrari and Wunsch 2009), modeled ocean-atmosphere interactions that are too weak (e.g., Cane 1998), or lack of modeled slow climate feedbacks related to carbon cycling or ice sheets (e.g., Lovejoy et al. 2013; Bakker et al. 2017). In terms of coral biases, environmental stress may alter biological fractionation of stable isotopes in some corals (Damassa et al. 2006), and few observations exist to calibrate coral records over centuryplus time scales. Moreover, proxies may track multiple climate variables. For example, coral isotope records reflect a mixed signal of temperature and salinity, which have distinct spectra of variability. Combining SST and sea surface salinity (SSS) in forward models shows that trends (one possible source of apparent low-frequency variability) in coral $\delta^{18} \mathrm{O}$ are consistent with modeled twentieth-century trends (Thompson et al. 2011).

The shape of the CMIP5-derived pseudocoral spectra closely resembles the shape of CMIP5 SST spectra, and local SSS is even more white than SST at the same geographic locations (Fig. 17). Therefore, including modeled SSS in our calculations does not resolve the 
a. CESM LME TS $\sigma$

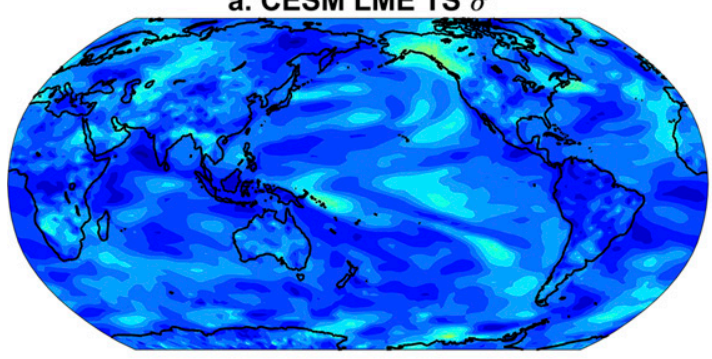

c. CMIP5 LM TS $\sigma$

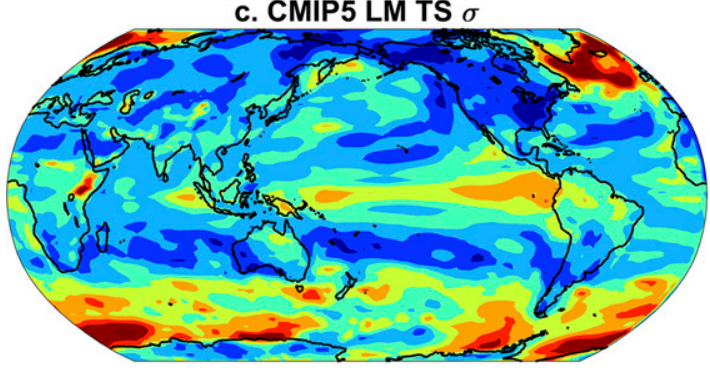

e. CMIP5 PIC TS $\sigma$

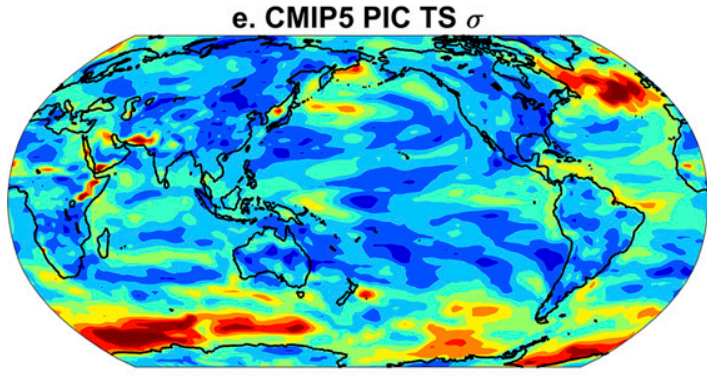

b. CESM LME PR $\sigma$

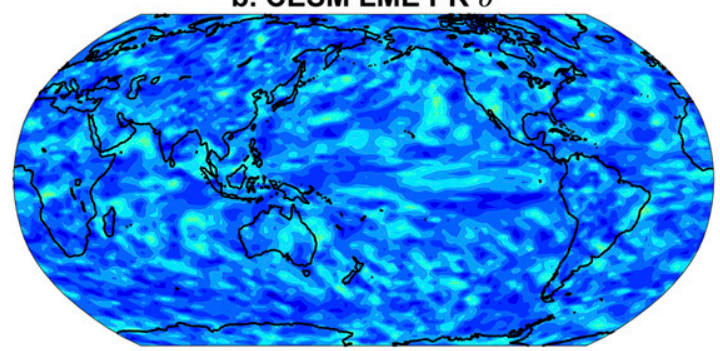

d. CMIP5 LM PR $\sigma$

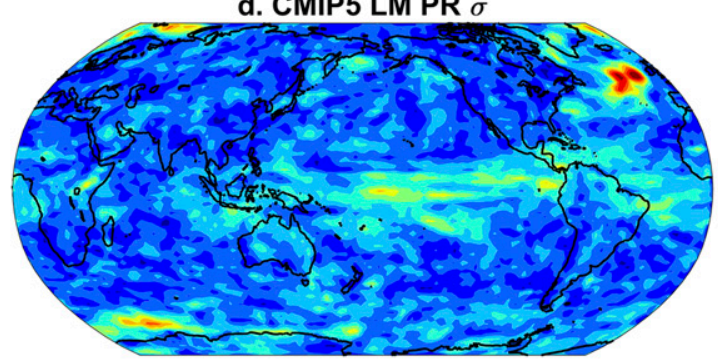

f. CMIP5 PIC PR $\sigma$

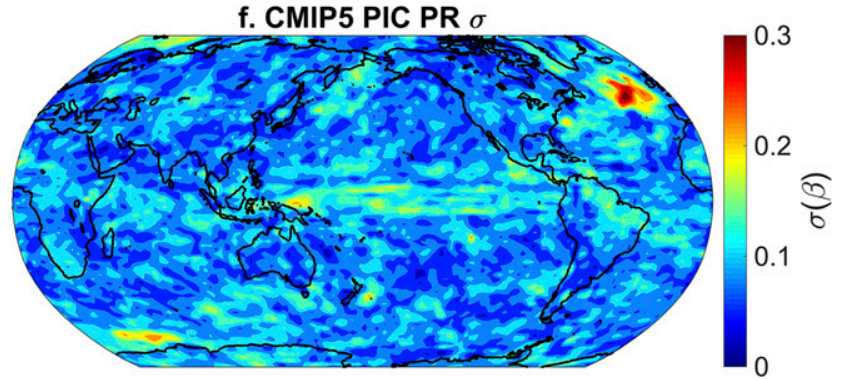

FIG. 14. Variability in the scaling $\beta$ of simulated temperature and precipitation. Standard deviation of $\beta$ values (blue, yellow, and red shading) in (a),(b) CESM LME, (c),(d) CMIP5 LM, and (e),(f) CMIP5 PIC simulations $>500 \mathrm{yr}$ in length that conducted the last millennium experiment for (left) surface temperature $\beta$ and (right) precipitation $\beta$.

coral-CMIP5 spectral mismatch. Although forward modeling of proxies using climate model data decreases much of the interannual paleo-model frequency disagreement, neither proxy forward modeling (e.g., Dee et al. 2017) nor inverse modeling (Laepple and Huybers 2014b) can remove the low-frequency (centennialmillennial scale) proxy-model mismatch. However, the proxy forward models used in these studies may exclude processes that influence low-frequency climate variability.

The mismatch between coral and modeled variance spectra may result from biases at either end of the frequency spectrum. Our coral analysis suggests that CMIP5 models may overestimate relative high- versus low-frequency variability in the tropical Pacific, consistent with previous work (e.g., Guilyardi et al. 2009; Ault et al. 2013a; Bellenger et al. 2014; Henriksson et al. 2015). However, individual proxy records of surface temperature indicate that CMIP5 models may underestimate local low-frequency temperature variability (Laepple and Huybers 2014b). Despite the presence of low-frequency internal processes in climate models, such as centennial-scale variations in Pacific SST, deep ocean circulation, and multicentury variability in interhemispheric ocean transport (Manabe and Stouffer 1996; Delworth and Zeng 2012; Karnauskas et al. 2012), paleodata show local low-frequency temperature variability that is up to 100 times stronger (Laepple and Huybers 2014b). This mismatch suggests that unless we are misinterpreting paleoclimate records, the latest generation of climate models substantially underrepresents low-frequency processes.

Additionally, missing or inaccurate external forcing estimates used in the CMIP5 LM experiment could explain part of the paleo-model mismatch. Although there is a short satellite record of solar activity, prior to the 

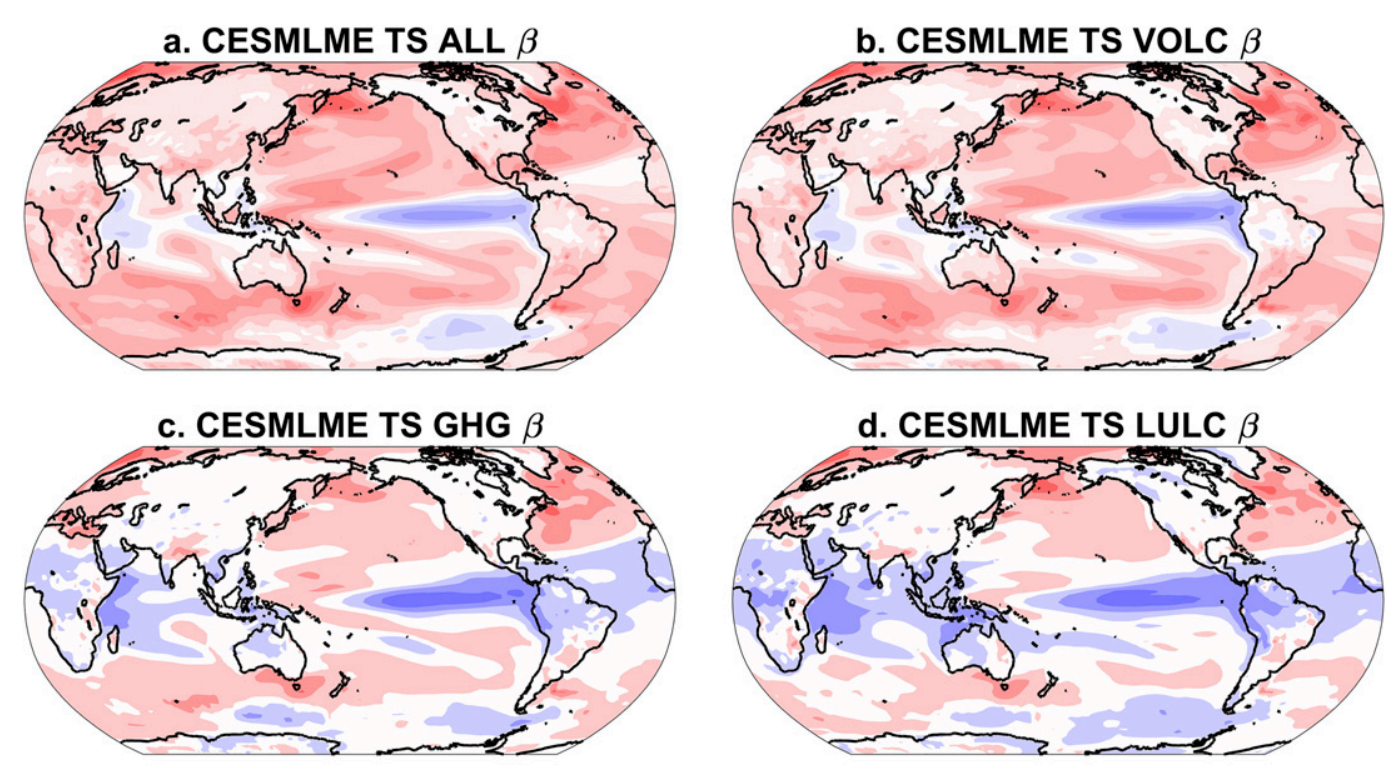

e. CESMLME TS ORB $\beta$
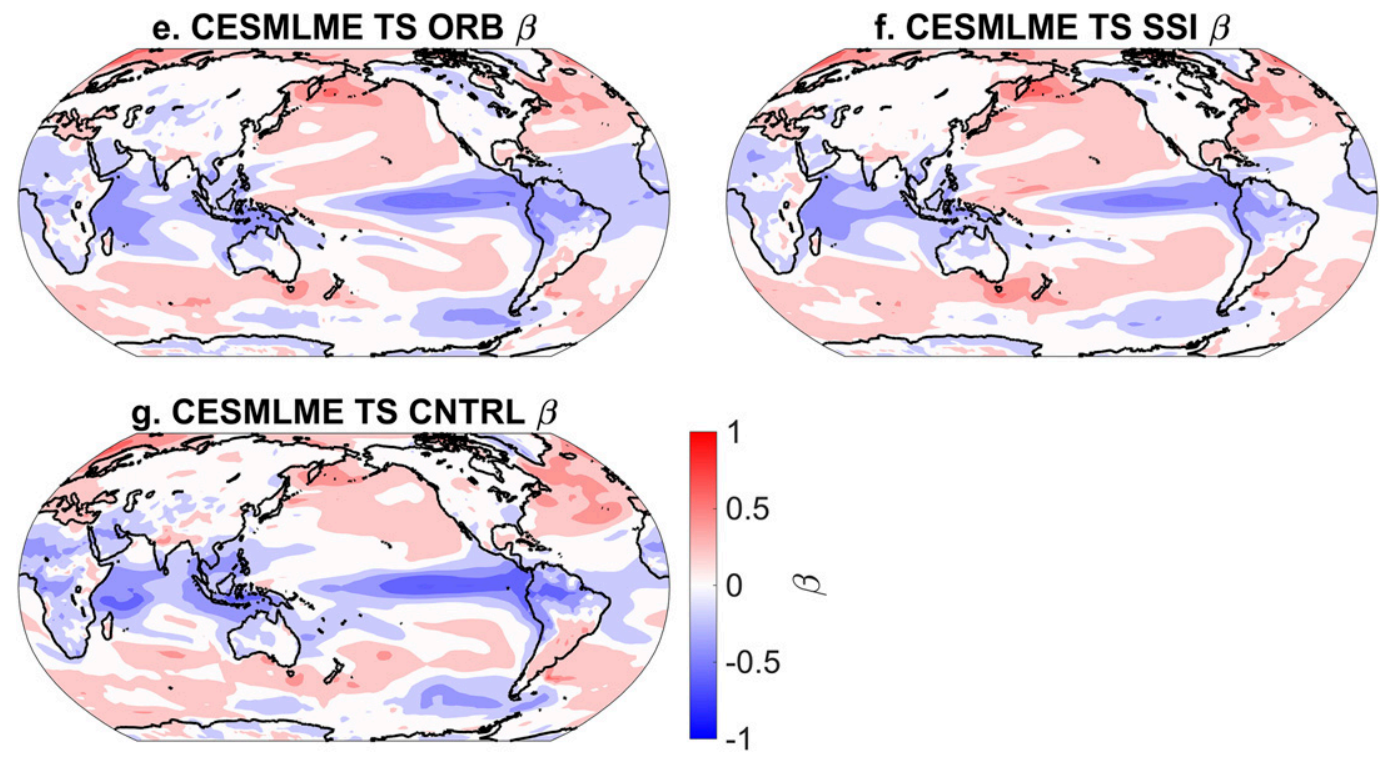

FIG. 15. Maps of mean temperature scaling $\beta$ from the CESM last millennium ensemble. Shading indicates mean surface temperature $\beta$ maps of (a) all-forcing $(N=10)$, (b) volcanic $(N=5)$, (c) greenhouse gas (pre-1850) $(N=3)$, (d) land use $(N=3)$, (e) orbital $(N=3)$, (f) solar $(N=3)$, and (g) control $(N=1)$ runs of this ensemble.

satellite era, proxy and geophysical measurements must be used to reconstruct solar activity, and the magnitude of this presatellite era solar activity is not well known (Schmidt et al. 2012). Furthermore, volcanic eruptions drive stratospheric aerosol concentrations in the last millennium experiment; these aerosols block solar radiation from reaching Earth's surface and help drive short-lived cooling in CMIP5 models (Masson-Delmotte et al. 2013). Various methods have been used to infer the pre-instrumental concentration of aerosols in the stratosphere; these methods often disagree in the magnitude of this forcing and each has particular errors and uncertainties (Gao et al. 2008; Crowley et al. 2008).

\section{e. Role of external forcing in temperature variance distributions}

External forcing, such as solar and orbital variability, is well expressed in multimillennial paleoclimate reconstructions (Masson-Delmotte et al. 2013). However, in a comparison of individual forcing runs over the past millennium in the CESM LME, solar and orbital forcing do not appreciably change the relative strength of low- versus high-frequency variance (Figs. 15e,f). An 

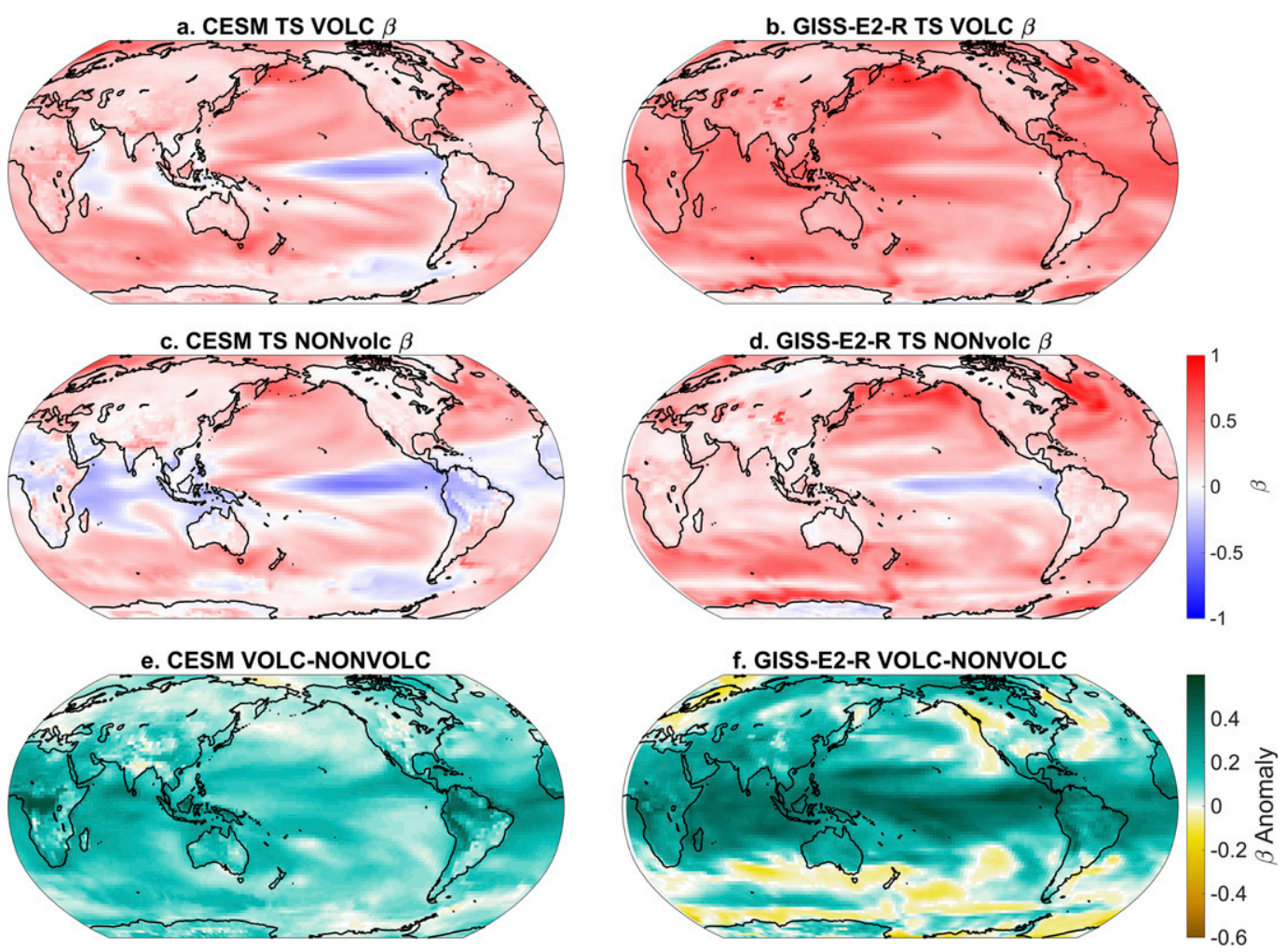

FIG. 16. Maps of temperature scaling $\beta$ for CESM LME and NASA GISS-E2-R volcanically and non-volcanically forced simulations. Surface temperature $\beta$ maps of (left) CESM LME and (right) GISS-E2-R LM mean (a),(b) volcanically forced, (c),(d) non-volcanically forced, and (e),(f) $\beta$ anomaly (volcanic - nonvolcanic) maps. The map in (a) includes the all-forcing $(N=10)$ and the volcanic-only forcing $(N=5)$ simulations. The map in (c) includes the control $(N=1)$, solar $(N=3)$, orbital $(N=3)$, land-use and land-cover $(N=3)$, and greenhouse gas $(N=3)$ simulations. The map in (b) includes simulations $(N=5)$ that also include solar, land-use and land-cover, greenhouse gas, and orbital forcing. The map in $(d)$ includes simulations $(N=2)$ that use solar, land-use and land-cover, greenhouse gas, and orbital forcing.

underestimation of the magnitude of solar forcing in the last millennium experiment, or the climate system's sensitivity to such forcing, could contribute to this paleomodel mismatch.

Various CMIP5 models also indicate that volcanic forcing increases long-period temperature variability in the climate system over both the last millennium and the instrumental era (Zhong et al. 2011; Laepple and Huybers 2014b; Henriksson et al. 2015; Vyushin et al. 2004; Vyushin and Kushner 2009). Indeed, the volcaniconly forcing in the CESM LME is the only external forcing that seems to appreciably increase simulated temperature $\beta$ values (Fig. 15).

Although external (volcanic) forcing appears to increase low-frequency temperature variance in the tropics in CMIP5, this forcing does not increase model temperature $\beta$ above $\operatorname{AR}(1) \beta$ values in the Pacific cold tongue region (Figs. 6a, 2, and 3). We suggest that simulated interannual ENSO variance dominates the spectrum in "strong ENSO" models (such as BCC_CSM1.1,
CCSM4, CESM, and FGOALS) and that external natural forcing is insufficient to overpower the simulated highfrequency tropical internal variability (Ault et al. 2013a). By contrast, ENSO variance plays a smaller role in the overall spectrum in "weak ENSO" models (such as GISS-E2-R). In these models, integration of shortlived volcanic forcing leads to a larger impact on temperature $\beta$ in the tropics (Figs. 6, 10, and 16). Outside the tropics, volcanic eruptions have a weaker impact on temperature values of $\beta$ in most CMIP5 models (Fig. 6), likely because 1) the temperature impact of eruptions is small compared to the large internal variability of temperature at high latitudes, and 2) lowfrequency internal variability already dominates the spectrum at high latitudes in CMIP5 PIC (Fig. 6), so volcanic forcing does not change the relationship of low- versus high-frequency variance.

The nonvolcanic, preindustrial forcings do not appreciably impact the $\beta$ values of temperature (Fig. 15). If the forcing estimates and the modeled climate 

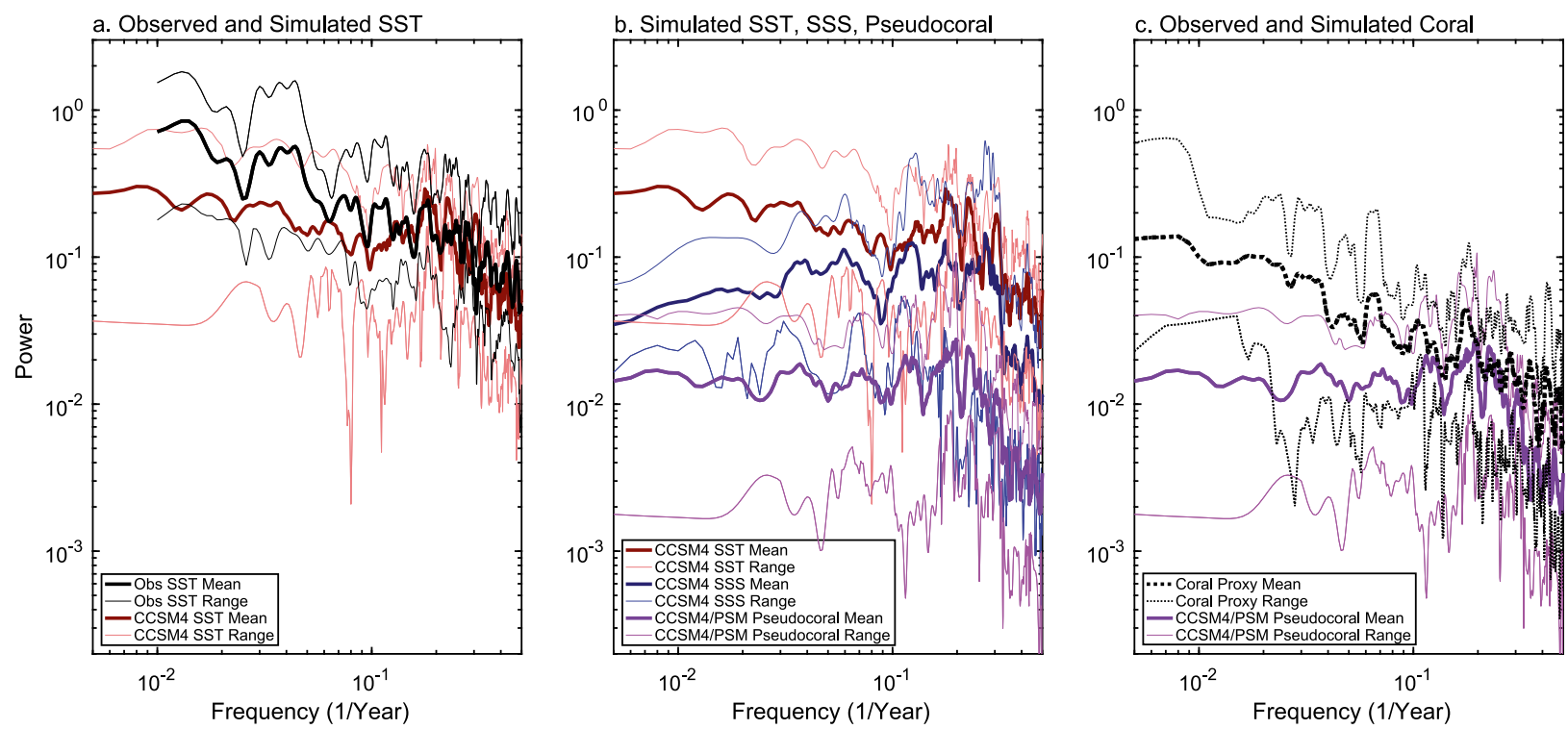

FIG. 17. (a) Instrumental and simulated SST; (b) simulated SST, SSS, and pseudocoral $\delta^{18} \mathrm{O}$; and (c) observed coral $\delta^{18} \mathrm{O}$ and simulated pseudocoral $\delta^{18} \mathrm{O}$ spectra at PAGES $2 \mathrm{k}$ network coral $\delta^{18} \mathrm{O}$ sites. Pseudocoral, temperature, and salinity data are from the NCAR CCSM 4 LM and HIST simulation years that overlap with the PAGES $2 \mathrm{k}$ coral data. CCSM4 pseudocoral $\delta^{18} \mathrm{O}$ calculated using the Thompson et al. (2011) forward model, which applies a linear regression to combine temperature and salinity variability. Time series were not normalized prior to spectral estimation, so pseudocoral $\delta^{18} \mathrm{O}$ (purple) and proxy $\delta^{18} \mathrm{O}$ (dashed black line) can be directly compared. CCSM 4 temperature (red) and instrumental temperature (black) spectra can also be directly compared. The salinity spectrum (blue) is in different units, so only the shape of the estimated spectra can be compared to the other variables. Light colors denote maximum and minimum spectral power across locations (see Table 2 for specific PAGES $2 \mathrm{k}$ site information), and dark lines denote mean of all sites. Instrumental temperature datasets listed in section 2 .

sensitivity to the forcing are correct, then this result suggests that volcanic forcing is the primary external forcing of simulated temperature of the preindustrial era in the last millennium (850-1850 CE). By contrast, paleoclimate records suggest that solar (and internal) variability influence decadal-centennial-scale temperature variability (Masson-Delmotte et al. 2013) and that temperature impacts of volcanic forcing are limited to interannual-decadal scales over the past $2000 \mathrm{yr}$ (Masson-Delmotte et al. 2013; Sigl et al. 2015).

\section{f. Role of external forcing in precipitation variance distributions}

Although volcanic forcing impacts the temperature spectrum in CESM and GISS-E2-R, external, preindustrial forcing has less impact on the modeled precipitation spectrum (Figs. 10d and 8d,f). Precipitation $\beta$ values in volcanically forced CMIP5 simulations are slightly higher than $\beta$ values in unforced simulations in the tropics and at higher latitudes in the Northern Hemisphere (Fig. 10). However, this result should be interpreted cautiously. Previous work suggests that in models, ENSO and the monsoon respond to volcanic forcing in the opposite direction of that indicated by paleoclimate records (Ault et al. 2013a; Anchukaitis et al. 2010). This ambiguity contrasts with the impacts of volcanic eruptions on temperature; paleoclimate data agree with models that volcanic aerosols cause at least short-lived cooling.

\section{g. Global impact of tropical Pacific variance}

Paleoclimate records from the tropical Pacific suggest that low-frequency temperature variability should dominate across the tropics, whereas CMIP5 models and the relatively short observation record suggest the temperature spectrum is either flat or dominated by interannual variance in the cold tongue region (Fig. 8). Tropical Pacific temperature variability has a near-global climate imprint (e.g., Trenberth et al. 1998); power-law behavior in the tropical Pacific therefore has the potential to impact variability in many regions. To examine this possibility, we compare models that simulate weak and strong low-frequency variability in the tropical $\mathrm{Pa}$ cific. The models that simulate a tropical Pacific dominated by high-frequency variability tend to experience less decadal-multidecadal drought in ENSO-teleconnected regions (Figs. 18a-d), whereas prolonged drought is more common in the models that simulate stronger lowfrequency Pacific variability. We also compare tropical Pacific temperature variability to global temperature 
a. WNA 11yr, 35yr Drought

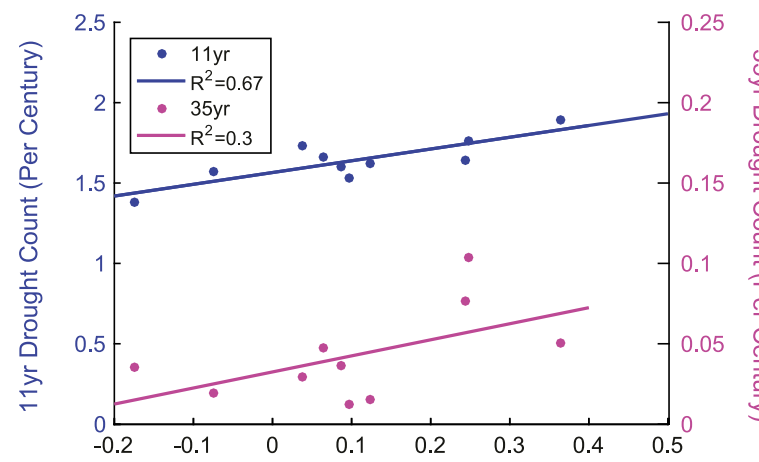

c. AMAZ 11yr, 35yr Drought

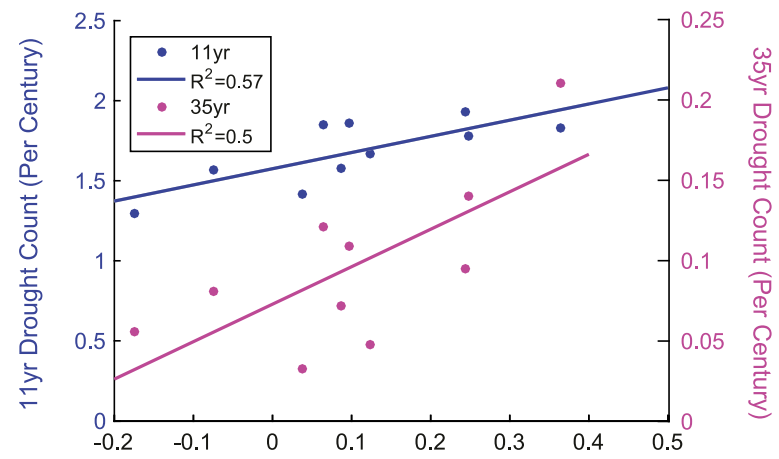

e. Global TS $\beta$

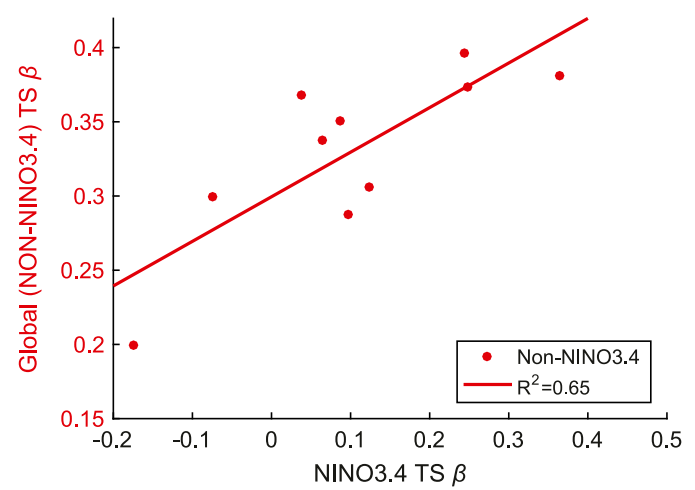

b. AUS 11yr, 35yr Drought

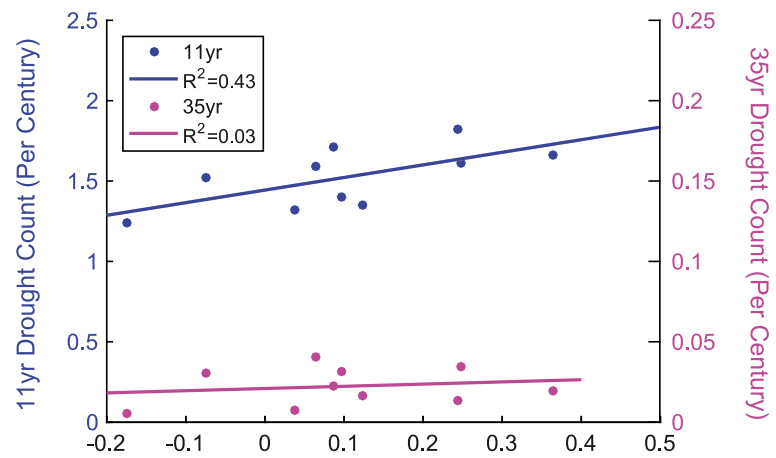

d. MIDEAST 11yr, 35yr Drought

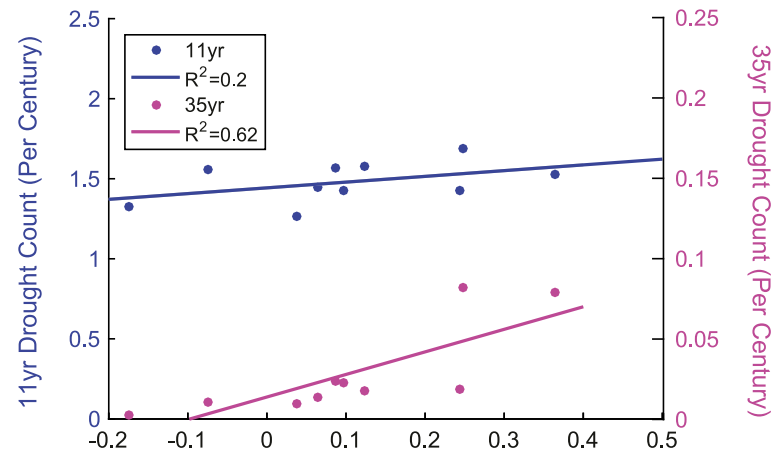

f. Global TS EOF1 $\beta$

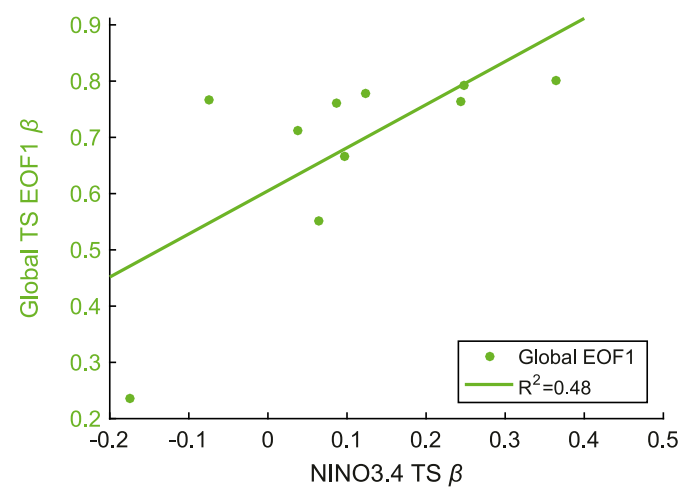

FIG. 18. Global impacts of CMIP5 LM Niño-3.4 region temperature scaling $\beta$. Scatterplots of mean Niño-3.4 region surface temperature $\beta$ value and mean per century 11- and 35-yr drought count in (a) WNA, (b) AUS, (c) AMAZ, and (d) MIDEAST in 10 CMIP5 LM simulations (850-1850 CE). Scatterplots of mean Niño-3.4 region surface temperature $\beta$ value and (e) global non-Niño-3.4 temperature $\beta$ and (f) global surface temperature EOF1 $\beta$. The $R^{2}$ values from least squares fit line are displayed in legend boxes (see section 2).

variability in CMIP5 LM and find a strong correlation between $\beta$ values in the Niño-3.4 region and global temperatures (Figs. 18e and 18f, respectively). Recent work related to the slowdown of recent atmospheric temperature increase supports our findings that Pacific climate variability influences global atmospheric temperature variability (e.g., Trenberth and Fasullo 2013; Dai et al. 2015; Thompson et al. 2015).
Although we observe a strong relationship among tropical Pacific $\beta$ and global temperature (and precipitation) $\beta$, correlation does not imply causation; tropical Pacific temperature $\beta$ may not directly impact global temperature and precipitation variance distributions. These different parts of the climate system may all experience low-frequency variability due to a combination of external forcing and internal dynamics that 
increases low-frequency variability globally and does not necessarily originate in the tropical Pacific. Nonetheless, maps of CESM temperature $\beta$ are strikingly similar to ENSO-teleconnection maps in this model. In fact, when we compare the absolute magnitude of the local ENSO temperature teleconnection to local $\beta$ from the same CESM simulation, we find a strong relationship $(r=-0.60)$. This finding suggests that interannual tropical Pacific variability can play an important role in shaping temperature variance distributions in ENSOteleconnected regions, and ENSO biases in models may impact regions far from the tropical Pacific.

\section{Summary and conclusions}

Accurate estimates of the spectrum of climate variability are essential to understanding the background dynamics of climate itself. Low-frequency climate variability likely arises from a combination of physical modes of variability and smoothing of weather noise by oceans (Manabe and Stouffer 1996). One outcome of our work is that we can identify where simulated climate variability could arise solely from local autocorrelation and where other factors also help determine the shape of the spectrum.

Our analysis of CMIP5 precipitation and temperature variability suggests that simulated precipitation is effectively atmospheric noise with little internal memory or low-frequency variability, regardless of forcing, except over isolated patches of mid- and high-latitude ocean regions (Figs. 12 and 13). By contrast, simulated temperature is slightly red on interannual-century time scales over most of the globe outside the tropics (Figs. 3 and 4) (Fredriksen and Rypdal 2016). Unforced CMIP5 models produce internally generated, significant lowfrequency temperature variability over most of the highlatitude oceans (Manabe and Stouffer 1996; Fredriksen and Rypdal 2016). However, unforced CMIP5 temperature scaling is difficult to distinguish from a simple $\mathrm{AR}(1)$ process across most of the tropics and midlatitudes; outside the central and eastern tropical Pacific much of this variability could arise from an integration of weather noise by thermal inertia in the oceans. In forced CMIP5 simulations of the last millennium, low-frequency temperature variability, especially in the tropics, appears to arise from the persistence of short-lived cooling from volcanic eruptions.

Many CMIP5 models suggest that the variance spectrum of tropical temperature and precipitation is dominated by interannual variability. By contrast, many paleoclimate records, including multicentennial coral records that should be robust at decade-century time scales, suggest that low-frequency variability dominates the last millennium across the tropical oceans. Although the tropical Pacific temperature spectrum in CMIP5 matches well with the spectrum from the instrumental record over interannual-decadal scales, the instrumental record is too short to accurately resolve multidecadal-centennial-scale frequencies, so we cannot independently test whether paleoclimate records or climate models are more accurately representing the low-frequency behavior of the climate system (Fig. 6a). The proxy-model mismatch could be attributed either to an unknown aspect of the proxy system or to model variance that is too strong on interannual scales and/or too weak on multidecadal-millennial scales (Laepple and Huybers 2014b), perhaps due to model and/or forcing issues.

Clearly, CMIP5 models and paleoclimate data paint drastically different pictures of the natural variability of tropical climate. Especially in the near term, the natural patterns of decade-century-scale variability will determine future climate and related risks. Understanding and anticipating these risks requires a deeper knowledge of the internal dynamics that lead to the apparent red continuum of climate variability.

Acknowledgments. The National Science Foundation EaSM2 Grant (AGS-1243125), the Directorate for Geosciences (Grant 3008610), and the Graduate Research Fellowship under Grant DGE-1143953 supported this work. We also thank the Kartchner Caverns scholarship fund and the Department of Geosciences at the University of Arizona for their funding support. J. Emile-Geay provided a script for normalizing precipitation time series. B. Otto-Bliesner at NCAR provided the CESM last millennium ensemble data. B. Otto-Bliesner, J. Fasullo, and S. Stevenson at NCAR also provided valuable feedback. We acknowledge the World Climate Research Programme's Working Group on Coupled Modelling, which is responsible for CMIP, and we thank the climate modeling groups (listed in Table 1) for producing and making available their model output. For CMIP the U.S. Department of Energy's Program for Climate Model Diagnosis and Intercomparison provides coordinating support and led development of software infrastructure in partnership with the Global Organization for Earth System Science Portals.

\section{REFERENCES}

Abram, N. J., M. K. Gagan, J. E. Cole, W. S. Hantoro, and M. Mudelsee, 2008: Recent intensification of tropical climate variability in the Indian Ocean. Nat. Geosci., 1, 849-853, doi:10.1038/ngeo357.

Ahmed, M., and Coauthors, 2013: Continental-scale temperature variability during the past two millennia. Nat. Geosci., 6, 339346, doi:10.1038/ngeo1797. 
Alibert, C., and L. Kinsley, 2008: A 170-year Sr/Ca and Ba/Ca coral record from the western Pacific warm pool: 1 . What can we learn from an unusual coral record? J. Geophys. Res., 113, C04008, doi:10.1029/2006JC003979.

Anchukaitis, K. J., B. M. Buckley, E. R. Cook, B. I. Cook, R. D. D'Arrigo, and C. M. Ammann, 2010: Influence of volcanic eruptions on the climate of the Asian monsoon region. Geophys. Res. Lett., 37, L22703, doi:10.1029/ 2010 GL044843.

Asami, R., T. Yamada, Y. Iryu, T. Quinn, C. Meyer, and G. Paulay, 2005: Interannual and decadal variability of the western Pacific sea surface condition for the years 1787-2000: Reconstruction based on stable isotope record from a Guam coral. J. Geophys. Res., 110, C05018, doi:10.1029/2004JC002555.

Ault, T. R., J. E. Cole, M. N. Evans, H. Barnett, N. J. Abram, A. W. Tudhope, and B. K. Linsley, 2009: Intensified decadal variability in tropical climate during the late 19th century. Geophys. Res. Lett., 36, L08602, doi:10.1029/2008GL036924.

_ C. Deser, M. Newman, and J. Emile-Geay, 2013a: Characterizing decadal to centennial variability in the equatorial Pacific during the last millennium. Geophys. Res. Lett., 40, 3450-3456, doi:10.1002/grl.50647.

—, J. E. Cole, J. T. Overpeck, G. T. Pederson, S. St. George, B. Otto-Bliesner, C. A. Woodhouse, and C. Deser, 2013b: The continuum of hydroclimate variability in western North America during the last millennium. J. Climate, 26, 5863-5878, doi:10.1175/JCLI-D-11-00732.1.

$,-\longrightarrow,-,-$, and D. M. Meko, 2014: Assessing the risk of persistent drought using climate model simulations and paleoclimate data. J. Climate, 27, 7529-7549, doi:10.1175/ JCLI-D-12-00282.1.

Bagnato, S., B. K. Linsley, S. S. Howe, G. M. Wellington, and J. Salinger, 2005: Coral oxygen isotope records of interdecadal climate variations in the South Pacific convergence zone region. Geochem. Geophys. Geosyst., 6, Q06001, doi:10.1029/ 2004GC000879.

Bakker, P., P. U. Clark, N. R. Golledge, A. Schmittner, and M. E. Weber, 2017: Centennial-scale Holocene climate variations amplified by Antarctic Ice Sheet discharge. Nature, 541, 72-76, doi:10.1038/nature20582.

Barsugli, J. J., and D. S. Battisti, 1998: The basic effects of atmosphere-ocean thermal coupling on midlatitude variability. J. Atmos. Sci., 55, 477-493, doi:10.1175/1520-0469(1998)055<0477: TBEOAO $>2.0 . \mathrm{CO} ; 2$

Bellenger, H., E. Guilyardi, J. Leloup, M. Lengaigne, and J. Vialard, 2014: ENSO representation in climate models: From CMIP3 to CMIP5. Climate Dyn., 42, 1999-2018, doi:10.1007/s00382-013-1783-z.

Bjerknes, J., 1964: Atlantic air-sea interaction. Advances in Geophysics, Vol. 10, Academic Press, 1-82, doi:10.1016/ S0065-2687(08)60005-9.

Blender, R., and K. Fraedrich, 2003: Long time memory in global warming simulations. Geophys. Res. Lett., 30, 1769, doi:10.1029/2003GL017666.

Boiseau, M., A. Juillet-Leclerc, P. Yiou, B. Salvat, P. Isdale, and M. Guillaume, 1998: Atmospheric and oceanic evidences of El Nino Southern Oscillation events in the south central Pacific Ocean from coral stable isotopic records over the last 137 years. Paleoceanography, 13, 671-685, doi:10.1029/98PA02502.

Cane, M. A., 1998: A role for the tropical Pacific. Science, 282, 5961, doi:10.1126/science.282.5386.59.

Charles, C., D. Hunter, and R. Fairbanks, 1997: Interaction between the ENSO and the Asian monsoon in a coral record of tropical climate. Science, 277, 925-928, doi:10.1126/ science.277.5328.925.

, K. Cobb, M. Moore, and R. Fairbanks, 2003: Monsoontropical ocean interaction in a network of coral records spanning the 20th century. Mar. Geol., 201, 207-222, doi:10.1016/S0025-3227(03)00217-2.

Cobb, K., C. Charles, and D. Hunter, 2001: A central tropical Pacific coral demonstrates Pacific, Indian, and Atlantic decadal climate connections. Geophys. Res. Lett., 28, 22092212, doi:10.1029/2001GL012919.

- — - H. Heng, and R. Edwards, 2003: El Nino/Southern Oscillation and tropical Pacific climate during the last millennium. Nature, 424, 271-276, doi:10.1038/nature01779.

—, N. Westphal, H. R. Sayani, J. T. Watson, E. Di Lorenzo, H. Cheng, R. L. Edwards, and C. D. Charles, 2013: Highly variable El Nino Southern Oscillation throughout the Holocene. Science, 339, 67-70, doi:10.1126/science.1228246.

Cole, J., R. Dunbar, T. McClanahan, and N. Muthiga, 2000: Tropical Pacific forcing of decadal SST variability in the western Indian Ocean over the past two centuries. Science, 287, 617-619, doi:10.1126/science.287.5453.617.

Crowley, T. J., G. Zielinski, B. Vinther, R. Udisti, K. Kreutzs, J. Cole-Dai, and E. Castellano, 2008: Volcanism and the Little Ice Age. PAGES Newsletter, Vol. 16 (3), PAGES International Project Office, Bern, Switzerland, 22-23, doi:10.22498/ pages.16.3.

Dai, A., J. C. Fyfe, S. Xie, and X. Dai, 2015: Decadal modulation of global surface temperature by internal climate variability. Nat. Climate Change, 5, 555-559, doi:10.1038/nclimate2605.

Damassa, T., J. Cole, H. Barnett, T. Ault, and T. McClanahan, 2006: Enhanced multidecadal climate variability in the seventeenth century from coral isotope records in the western Indian Ocean. Paleoceanography, 21, PA2016, doi:10.1029/ 2005PA001217.

Dee, S. G., L. A. Parsons, G. R. Loope, J. T. Overpeck, T. R. Ault, and J. Emile-Geay, 2017: Improved spectral comparisons of paleoclimate models and observations via proxy system modeling: Implications for multi-decadal variability. Earth Planet. Sci. Lett., 476, 34-46, doi:10.1016/j.epsl.2017.07.036.

DeLong, K. L., T. M. Quinn, F. W. Taylor, K. Lin, and C. Shen, 2012: Sea surface temperature variability in the southwest tropical Pacific since AD 1649. Nat. Climate Change, 2, 799804, doi:10.1038/nclimate1583.

Delworth, T. L., and F. Zeng, 2012: Multicentennial variability of the Atlantic meridional overturning circulation and its climatic influence in a 4000 year simulation of the GFDL CM2.1 climate model. Geophys. Res. Lett., 39, L13702, doi:10.1029/ 2012GL052107.

Deser, C., M. A. Alexander, S. Xie, and A. S. Phillips, 2010: Sea surface temperature variability: Patterns and mechanisms. Annu. Rev. Mar. Sci., 2, 115-143, doi:10.1146/ annurev-marine-120408-151453.

Ditlevsen, P., H. Svensmark, and S. Johnsen, 1996: Contrasting atmospheric and climate dynamics of the last-glacial and Holocene periods. Nature, 379, 810-812, doi:10.1038/379810a0.

Druffel, E., and S. Griffin, 1999: Variability of surface ocean radiocarbon and stable isotopes in the southwestern Pacific. J. Geophys. Res., 104, 23 607-23 613, doi:10.1029/ 1999JC900212.

Dunbar, R., G. Wellington, M. Colgan, and P. Glynn, 1994: Eastern Pacific sea surface temperature since 1600 A.D.: The $\delta^{18} \mathrm{O}$ record of climate variability in Galápagos corals. Paleoceanography, 9, 291-315, doi:10.1029/93PA03501. 
Fairbanks, R., M. Evans, J. Rubenstone, R. Mortlock, K. Broad, M. Moore, and C. Charles, 1997: Evaluating climate indices and their geochemical proxies measured in corals. Coral Reefs, 16 (Suppl.), S93-S100, doi:10.1007/ s003380050245.

Ferrari, R., and C. Wunsch, 2009: Ocean circulation kinetic energy: Reservoirs, sources, and sinks. Annu. Rev. Fluid Mech., 41, 253-282, doi:10.1146/annurev.fluid.40.111406.102139.

Fraedrich, K., and R. Blender, 2003: Scaling of atmosphere and ocean temperature correlations in observations and climate models. Phys. Rev. Lett., 90, 108501, doi:10.1103/ PhysRevLett.90.108501.

_- U. Luksch, and R. Blender, 2004: 1/f model for long-time memory of the ocean surface temperature. Phys. Rev., 70E, 037301, doi:10.1103/PhysRevE.70.037301.

Franke, J., D. Frank, C. C. Raible, J. Esper, and S. Broennimann, 2013: Spectral biases in tree-ring climate proxies. Nat. Climate Change, 3, 360-364, doi:10.1038/nclimate1816.

Frankignoul, C., and K. Hasselmann, 1977: Stochastic climate models, part II: Application to sea-surface temperature anomalies and thermocline variability. Tellus, 29A, 289-305, doi:10.3402/tellusa.v29i4.11362.

Fredriksen, H., and K. Rypdal, 2016: Spectral characteristics of instrumental and climate model surface temperatures. J. Climate, 29, 1253-1268, doi:10.1175/JCLI-D-15-0457.1.

Gao, C., A. Robock, and C. Ammann, 2008: Volcanic forcing of climate over the past 1500 years: An improved ice core-based index for climate models. J. Geophys. Res., 113, D23111, doi:10.1029/2008JD010239.

Gorman, M. K., and Coauthors, 2012: A coral-based reconstruction of sea surface salinity at Sabine Bank, Vanuatu from 1842 to 2007 CE. Paleoceanography, 27, PA3226, doi:10.1029/ 2012PA002302.

Grove, C. A., and Coauthors, 2013: Madagascar corals reveal a multidecadal signature of rainfall and river runoff since 1708 . Climate Past, 9, 641-656, doi:10.5194/cp-9-641-2013.

Guilderson, T., and D. Schrag, 1999: Reliability of coral isotope records from the western Pacific warm pool: A comparison using age-optimized records. Paleoceanography, 14, 457-464, doi:10.1029/1999PA900024.

Guilyardi, E., A. Wittenberg, A. Fedorov, M. Collins, C. Wang, A. Capotondi, G. J. van Oldenborgh, and T. Stockdale, 2009: Understanding El Niño in ocean-atmosphere general circulation models: Progress and challenges. Bull. Amer. Meteor. Soc., 90, 325-340, doi:10.1175/2008BAMS2387.1.

Hasselmann, K., 1976: Stochastic climate models: Part I. Theory. Tellus, 28A, 473-485, doi:10.3402/tellusa.v28i6.11316.

Henriksson, S. V., P. Raisanen, J. Silen, H. Jarvinen, and A. Laaksonen, 2015: Improved power-law estimates from multiple samples provided by millennium climate simulations. Theor. Appl. Climatol., 119, 667-677, doi:10.1007/ s00704-014-1132-0.

Huang, B., and Coauthors, 2015: Extended Reconstructed Sea Surface Temperature version 4 (ERSST.v4). Part I: Upgrades and intercomparisons. J. Climate, 28, 911-930, doi:10.1175/ JCLI-D-14-00006.1.

Huybers, P., and W. Curry, 2006: Links between annual, Milankovitch and continuum temperature variability. Nature, 441, 329-332, doi:10.1038/nature04745.

Kaplan, A., M. Cane, Y. Kushnir, A. Clement, M. Blumenthal, and B. Rajagopalan, 1998: Analyses of global sea surface temperature 1856-1991. J. Geophys. Res., 103, 18567-18589, doi:10.1029/97JC01736.
Karnauskas, K. B., J. E. Smerdon, R. Seager, and J. F. GonzálezRouco, 2012: A Pacific centennial oscillation predicted by coupled GCMs. J. Climate, 25, 5943-5961, doi:10.1175/ JCLI-D-11-00421.1.

Kuhnert, H., J. Patzold, B. Hatcher, K. Wyrwoll, A. Eisenhauer, L. Collins, Z. Zhu, and G. Wefer, 1999: A 200-year coral stable oxygen isotope record from a high-latitude reef off western Australia. Coral Reefs, 18, 1-12, doi:10.1007/s003380050147.

$\_, \ldots$, K. Wyrwoll, and G. Wefer, 2000: Monitoring climate variability over the past 116 years in coral oxygen isotopes from Ningaloo Reef, Western Australia. Int. J. Earth Sci., 88 , 725-732, doi:10.1007/s005310050300.

Kutzbach, J., and R. Bryson, 1974: Variance spectrum of Holocene climatic fluctuations in North Atlantic sector. J. Atmos. Sci., 31, 1958-1963, doi:10.1175/1520-0469(1974)031<1958: VSOHCF $>2.0 . \mathrm{CO} ; 2$.

Laepple, T., and P. Huybers, 2013: Reconciling discrepancies between $\mathrm{Uk} 37$ and $\mathrm{Mg} / \mathrm{Ca}$ reconstructions of Holocene marine temperature variability. Earth Planet. Sci. Lett., 375, 418-429, doi:10.1016/j.eps1.2013.06.006.

$\longrightarrow$, and - 2014a: Global and regional variability in marine surface temperatures. Geophys. Res. Lett., 41, 2528-2534, doi:10.1002/2014GL059345.

$\longrightarrow$, and $\longrightarrow$, 2014b: Ocean surface temperature variability: Large model-data differences at decadal and longer periods. Proc. Natl. Acad. Sci. USA, 111, 16 682-16687, doi:10.1073/ pnas.1412077111.

Lemke, P., 1977: Stochastic climate models, part 3. Application to zonally averaged energy models. Tellus, 29, 385-392, doi:10.3402/tellusa.v29i5.11371.

Linsley, B., R. Dunbar, G. Wellington, and D. Mucciarone, 1994: A coral-based reconstruction of intertropical convergence zone variability over Central America since 1707. J. Geophys. Res., 99, 9977-9994, doi:10.1029/94JC00360.

—, G. Wellington, and D. Schrag, 2000a: Decadal sea surface temperature variability in the subtropical South Pacific from 1726 to 1997 AD. Science, 290, 1145-1148, doi:10.1126/ science.290.5494.1145.

— L. Ren, R. Dunbar, and S. Howe, 2000b: El Niño Southern Oscillation (ENSO) and decadal-scale climate variability at $10^{\circ} \mathrm{N}$ in the eastern Pacific from 1893 to 1994: A coral-based reconstruction from Clipperton Atoll. Paleoceanography, 15, 322-335, doi:10.1029/1999PA000428.

_ G. Wellington, D. Schrag, L. Ren, M. Salinger, and A. Tudhope, 2004: Geochemical evidence from corals for changes in the amplitude and spatial pattern of South Pacific interdecadal climate variability over the last 300 years. Climate Dyn., 22, 1-11, doi:10.1007/s00382-003-0364-y.

_- A. Kaplan, Y. Gouriou, J. Salinger, P. deMenocal, G. Wellington, and S. Howe, 2006: Tracking the extent of the South Pacific convergence zone since the early 1600s. Geochem. Geophys. Geosyst., 7, Q05003, doi:10.1029/2005GC001115.

Lough, J. M., 2011: Great Barrier Reef coral luminescence reveals rainfall variability over northeastern Australia since the 17th century. Paleoceanography, 26, PA2201, doi:10.1029/ 2010PA002050.

Lovejoy, S., D. Schertzer, and D. Varon, 2013: Do GCMs predict the climate ... or macroweather? Earth Syst. Dyn., 4, 439-454, doi:10.5194/esd-4-439-2013.

MacMartin, D. G., E. Tziperman, and L. Zanna, 2013: Frequency domain multimodel analysis of the response of Atlantic meridional overturning circulation to surface forcing. J. Climate, 26, 8323-8340, doi:10.1175/JCLI-D-12-00717.1. 
Manabe, S., and R. Stouffer, 1996: Low-frequency variability of surface air temperature in a 1000-year integration of a coupled atmosphere-ocean-land surface model. J. Climate, 9, 376-393, doi:10.1175/1520-0442(1996)009<0376: LFVOSA $>2.0 . \mathrm{CO} ; 2$.

Masson-Delmotte, V., and Coauthors, 2013: Information from paleoclimate archives. Climate Change 2013: The Physical Science Basis, T. F. Stocker et al., Eds., Cambridge University Press, 383-464.

McGregor, H. V., M. J. Fischer, M. K. Gagan, D. Fink, S. J. Phipps, H. Wong, and C. D. Woodroffe, 2013: A weak El Niño/ Southern Oscillation with delayed seasonal growth around 4,300 years ago. Nat. Geosci., 6, 949-953, doi:10.1038/ ngeo1936.

Morice, C. P., J. J. Kennedy, N. A. Rayner, and P. D. Jones, 2012: Quantifying uncertainties in global and regional temperature change using an ensemble of observational estimates: The HadCRUT4 data set. J. Geophys. Res., 117, D08101, doi:10.1029/2011JD017187.

Nakamura, N., H. Kayanne, H. Iijima, T. R. McClanahan, S. K. Behera, and T. Yamagata, 2009: Mode shift in the Indian Ocean climate under global warming stress. Geophys. Res. Lett., 36, L23708, doi:10.1029/2009GL040590.

Neumaier, A., and T. Schneider, 2001: Estimation of parameters and eigenmodes of multivariate autoregressive models. $A C M$ Trans. Math. Software, 27, 27-57, doi:10.1145/382043.382304.

Newman, M., G. Compo, and M. Alexander, 2003: ENSO-forced variability of the Pacific decadal oscillation. J. Climate, 16, 3853-3857, doi:10.1175/1520-0442(2003)016<3853: EVOTPD $>2.0 . \mathrm{CO} ; 2$.

_ and Coauthors, 2016: The Pacific decadal oscillation, revisited. J. Climate, 29, 4399-4427, doi:10.1175/JCLI-D-15-0508.1.

Nurhati, I. S., K. M. Cobb, and E. Di Lorenzo, 2011: Decadal-scale SST and salinity variations in the central tropical Pacific: Signatures of natural and anthropogenic climate change. J. Climate, 24, 3294-3308, doi:10.1175/2011JCLI3852.1.

Osborne, M. C., R. B. Dunbar, D. A. Mucciarone, E. Druffel, and J. Sanchez-Cabeza, 2014: A 215-yr coral $\delta^{18} \mathrm{O}$ time series from Palau records dynamics of the west Pacific warm pool following the end of the Little Ice Age. Coral Reefs, 33, 719-731, doi:10.1007/s00338-014-1146-1.

Otto-Bliesner, B., and Coauthors, 2015: Climate variability and change since $850 \mathrm{CE}$ : An ensemble approach with the Community Earth System Model. Bull. Amer. Meteor. Soc., 97, 735-754, doi:10.1175/BAMS-D-14-00233.1.

Pelletier, J., 1998: The power spectral density of atmospheric temperature from time scales of $10^{-2}$ to $10^{6} \mathrm{yr}$. Earth Planet Sci. Lett., 158, 157-164, doi:10.1016/S0012-821X(98)00051-X.

_ , and D. Turcotte, 1997: Long-range persistence in climatological and hydrological time series: Analysis, modeling and application to drought hazard assessment. J. Hydrol., 203, 198-208, doi:10.1016/S0022-1694(97)00102-9.

Pfeiffer, M., O. Timm, W. Dullo, and S. Podlech, 2004: Oceanic forcing of interannual and multidecadal climate variability in the southwestern Indian Ocean: Evidence from a 160 year coral isotopic record (La Réunion, $55^{\circ} \mathrm{E}, 21^{\circ} \mathrm{S}$ ). Paleoceanography, 19, PA4006, doi:10.1029/2003PA000964.

Quinn, T., T. Crowley, and F. Taylor, 1996: New stable isotope results from a 173-year coral from Espiritu Santo, Vanuatu. Geophys. Res. Lett., 23, 3413-3416, doi:10.1029/96GL03169.

, C. Henin, P. Joannot, and Y. Join, 1998: A multicentury stable isotope record from a New Caledonia coral: Interannual and decadal sea surface temperature variability in the southwest Pacific since 1657 AD. Paleoceanography, 13, 412-426, doi:10.1029/98PA00401.

, F. Taylor, and T. Crowley, 2006: Coral-based climate variability in the western Pacific warm pool since 1867. J. Geophys. Res., 111, C11006, doi:10.1029/2005JC003243.

Rayner, N., D. Parker, E. Horton, C. Folland, L. Alexander, D. Rowell, E. Kent, and A. Kaplan, 2003: Global analyses of sea surface temperature, sea ice, and night marine air temperature since the late nineteenth century. J. Geophys. Res., 108, 4407, doi:10.1029/2002JD002670.

Roe, G. H., and M. B. Baker, 2016: The response of glaciers to climatic persistence. J. Glaciol., 62, 440-450, doi:10.1017/ jog.2016.4.

Russell, J. L., R. J. Stouffer, and K. W. Dixon, 2006: Intercomparison of the Southern Ocean circulations in IPCC coupled model control simulations. J. Climate, 19, 4560-4575, doi:10.1175/JCLI3869.1.

Schmidt, G. A., and Coauthors, 2012: Climate forcing reconstructions for use in PMIP simulations of the last millennium (v1.1). Geosci. Model Dev., 5, 185-191, doi:10.5194/gmd-5-185-2012.

Sen Gupta, A., N. C. Jourdain, J. N. Brown, and D. Monselesan, 2013: Climate drift in the CMIP5 models. J. Climate, 26, $8597-$ 8615, doi:10.1175/JCLI-D-12-00521.1.

Shuman, B., 2012: Patterns, processes, and impacts of abrupt climate change in a warm world: The past 11,700 years. Wiley Interdiscip. Rev.: Climate Change, 3, 19-43, doi:10.1002/wcc.152.

Sigl, M., and Coauthors, 2015: Timing and climate forcing of volcanic eruptions for the past 2,500 years. Nature, 523, 543, doi:10.1038/nature14565.

Smith, T. M., R. W. Reynolds, R. E. Livezey, and D. C. Stokes, 1996: Reconstruction of historical sea surface temperatures using empirical orthogonal functions. J. Climate, 9, 1403-1420, doi:10.1175/1520-0442(1996)009<1403:ROHSST>2.0.CO;2.

Taylor, K. E., R. J. Stouffer, and G. A. Meehl, 2012: An overview of CMIP5 and the experiment design. Bull. Amer. Meteor. Soc., 93, 485-498, doi:10.1175/BAMS-D-11-00094.1.

Thomson, D. J., 1982: Spectrum estimation and harmonic-analysis. Proc. IEEE, 70, 1055-1096, doi:10.1109/PROC.1982.12433.

Thompson, D. M., T. R. Ault, M. N. Evans, J. E. Cole, and J. EmileGeay, 2011: Comparison of observed and simulated tropical climate trends using a forward model of coral $\delta^{18} \mathrm{O}$. Geophys. Res. Lett., 38, L14706, doi:10.1029/2011GL048224.

, J. E. Cole, G. T. Shen, A. W. Tudhope, and G. A. Meehl, 2015: Early twentieth-century warming linked to tropical Pacific wind strength. Nat. Geosci., 8, 117-121, doi:10.1038/ngeo2321.

Thornalley, D. J. R., H. Elderfield, and I. N. McCave, 2009: Holocene oscillations in temperature and salinity of the surface subpolar North Atlantic. Nature, 457, 711-714, doi:10.1038/ nature 07717 .

Trenberth, K. E., and J. T. Fasullo, 2013: An apparent hiatus in global warming? Earth's Future, 1, 19-32, doi:10.1002/ 2013EF000165.

G. W. Branstator, D. Karoly, A. Kumar, N. Lau, and C. Ropelewski, 1998: Progress during TOGA in understanding and modeling global teleconnections associated with tropical sea surface temperatures. J. Geophys. Res., 103, 14 291-14324, doi:10.1029/97JC01444.

Tudhope, A., and Coauthors, 2001: Variability in the El NiñoSouthern Oscillation through a glacial-interglacial cycle. Science, 291, 1511-1517, doi:10.1126/science.1057969.

Urban, F. E., J. E. Cole, and J. T. Overpeck, 2000: Influence of mean climate change on climate variability from a 155 -year tropical Pacific coral record. Nature, 407, 989-993, doi:10.1038/35039597. 
Valdes, P., 2011: Built for stability. Nat. Geosci., 4, 414-416, doi:10.1038/ngeo1200.

Van Albada, S., and P. Robinson, 2007: Transformation of arbitrary distributions to the normal distribution with application to EEG test-retest reliability. J. Neurosci. Methods, 161, 205211, doi:10.1016/j.jneumeth.2006.11.004.

Vyushin, D. I., and P. J. Kushner, 2009: Power-law and longmemory characteristics of the atmospheric general circulation. J. Climate, 22, 2890-2904, doi:10.1175/2008JCLI2528.1.

, I. Zhidkov, S. Havlin, A. Bunde, and S. Brenner, 2004: Volcanic forcing improves atmosphere-ocean coupled general circulation model scaling performance. Geophys. Res. Lett., 31, L10206, doi:10.1029/2004GL019499.

Wittenberg, A. T., 2009: Are historical records sufficient to constrain ENSO simulations? Geophys. Res. Lett., 36, L12702, doi:10.1029/2009GL038710.

Zebiak, S. E., and M. A. Cane, 1987: A model El Niño-Southern Oscillation. Mon. Wea. Rev., 115, 2262-2278, doi:10.1175/ 1520-0493(1987)115<2262:AMENO>2.0.CO;2.
Zhong, Y., G. H. Miller, B. L. Otto-Bliesner, M. M. Holland, D. A. Bailey, D. P. Schneider, and A. Geirsdottir, 2011: Centennialscale climate change from decadally-paced explosive volcanism: A coupled sea ice-ocean mechanism. Climate Dyn., 37, 2373-2387, doi:10.1007/s00382-010-0967-z.

Zinke, J., W. Dullo, G. Heiss, and A. Eisenhauer, 2004: ENSO and Indian Ocean subtropical dipole variability is recorded in a coral record off southwest Madagascar for the period 1659 to 1995. Earth Planet. Sci. Lett., 228, 177-194, doi:10.1016/ j.eps1.2004.09.028.

— M. Pfeiffer, O. Timm, W.-C. Dullo, D. Kroon, and B. A. Thomassin, 2008: Mayotte coral reveals hydrological changes in the western Indian Ocean between 1881 and 1994. Geophys. Res. Lett., 35, L23707, doi:10.1029/2008GL035634.

,,,---- , and G. J. A. Brummer, 2009: Western Indian Ocean marine and terrestrial records of climate variability: A review and new concepts on land-ocean interactions since AD 1660. Int. J. Earth Sci., 98, 115-133, doi:10.1007/ s00531-008-0365-5. 